\title{
BLOGGING IN A VIRTUAL LEARNING COMMUNITY: HOW DOES IT SUPPORT \\ CONTINUOUS PROFESSIONAL LEARNING FOR ONTARIO REGISTERED \\ EARLY CHILDHOOD EDUCATORS?
}

By

Shannon Sveda

Diploma in Early Childhood Education, Sheridan College, 2005

Bachelor of Arts in Early Childhood Studies, Ryerson University, 2013

\section{A MRP presented to Ryerson University}

In partial fulfillment of the requirements for the degree of

Master of Arts

in the Program of

Early Childhood Studies

Toronto, Ontario, Canada, 2015

(C) Shannon Sveda 2015 


\section{AUTHOR'S DECLARATION FOR ELECTRONIC SUBMISSION OF A MRP}

I hereby declare that I am the sole author of this MRP. This is a true copy of the MRP, including any required final revisions.

I authorize Ryerson University to lend this MRP to other institutions or individuals for the purpose of scholarly research.

I further authorize Ryerson University to reproduce this MRP by photocopying or by other means, in total or in part, at the request of other institutions or individuals for the purpose of scholarly research.

I understand that my MRP may be made electronically available to the public. 


\begin{abstract}
Blogging in a virtual learning community: How does it support continuous professional learning for Ontario registered early childhood educators?
\end{abstract}

Master of Arts, 2015

Shannon Sveda

Program of Early Childhood Studies,

Ryerson University

This research study examined the use of blogging as a medium for professional learning for registered early childhood educators (RECEs) in Ontario. Although educators are more frequently turning to blogs, social media, and virtual learning communities for their professional learning, there is a limited amount of previous research which has examined the use and efficacy of these mediums for that purpose. Using grounded theory, and guided by a social constructivist framework, I gathered data from blog posts and comments written by a small group of RECEs practicing in Ontario, and conducted interviews at two intervals to gather their perceptions of the blogging experience. While further study is needed to address potential barriers which may hinder RECEs from using blogging, I found that there were benefits in the use of blogging as a medium for reflection, building a professional community, and professional learning. 


\section{Acknowledgements}

First and foremost, I would like to express my deepest thanks to the participants in this study. Thank you for your willingness to try out a new medium for professional learning, and for sharing your honest impressions with me. It was a pleasure to read about your practices, and to talk with you about your experiences.

I would also like to thank my fellow MRP students for their feedback and support. It has been a great pleasure to share this journey with you all. A special thanks to Natalya Androsova, our mentor and cheerleader. Thank you for sharing your own experiences and knowledge, but more than that, thank you for your never-ending positivity.

I would like to express my great appreciation to Dr. Rachel Langford, my MRP supervisor, for her professional guidance and support. I would also like to thank Dr. Mehrunnisa Ali and Dr. Kathleen Peets, my MRP defense panel, for their thoughtful questions and feedback.

Finally, I would like to thank my friends and family for their encouragement, patience, and support this past year. In particular my husband, Paul Sveda, who is my most trusted sounding board. Thank you for always believing in me, and for always reminding me to believe in myself. 


\section{Table of Contents}

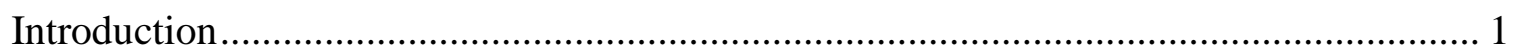

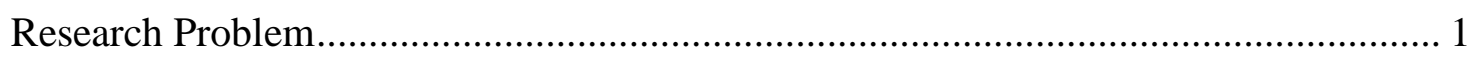

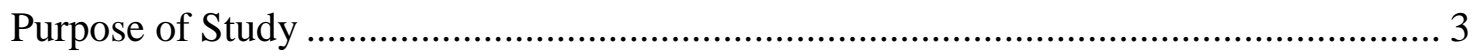

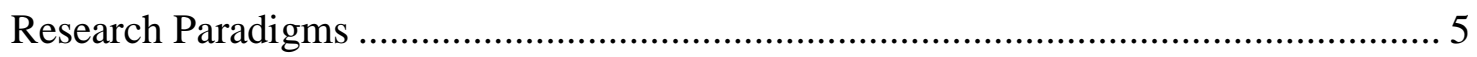

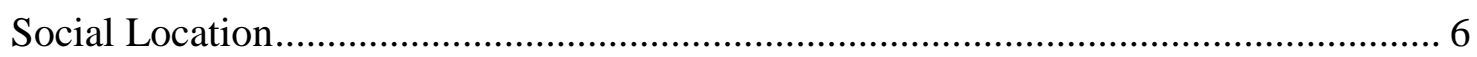

Conceptual Framework and Literature Review …………………….............................. 7

Professional Learning...................................................................................................... 7

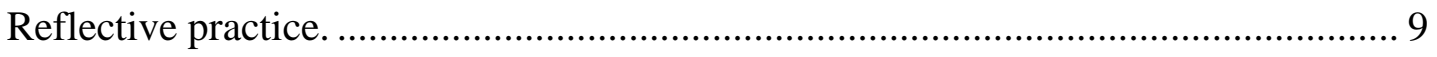

Blogging as reflective practice. .............................................................................. 12

Communities of Practice ........................................................................................... 15

Virtual learning communities.................................................................................. 16

Development of learning communities..................................................................... 17

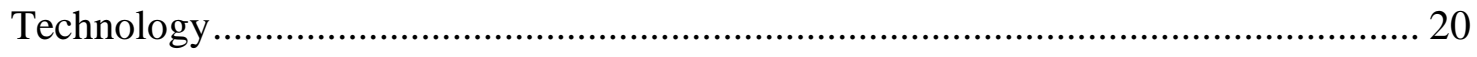

Advantages and disadvantages of blogs............................................................. 21

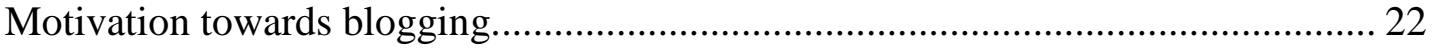

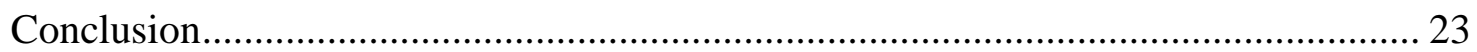

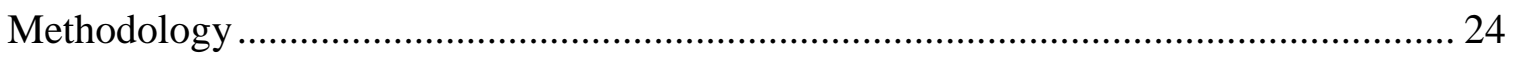

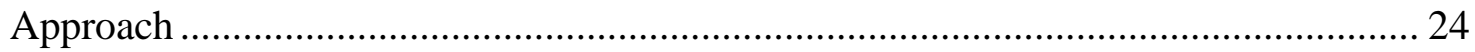

Strategy

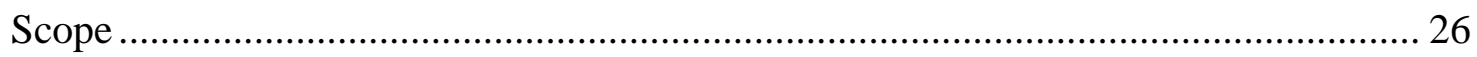

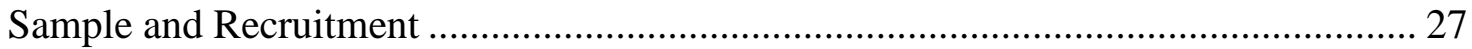

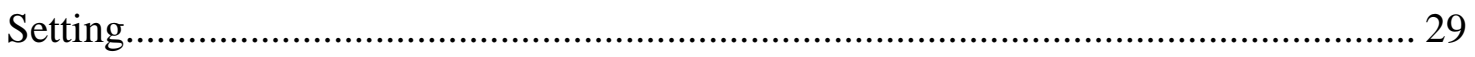

Data Collection.................................................................................................... 30

Interview data. ...................................................................................................... 31

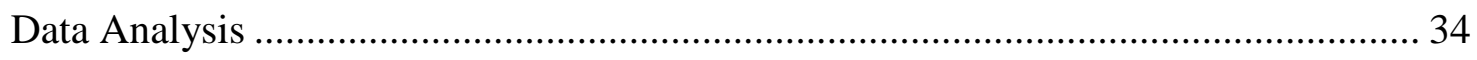

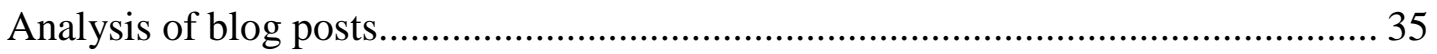

Analysis of blog comments. ................................................................................. 36

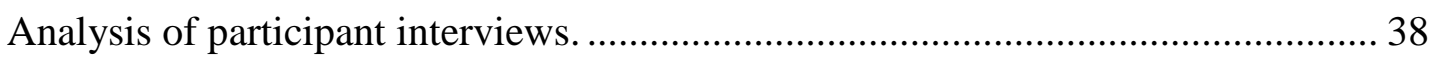

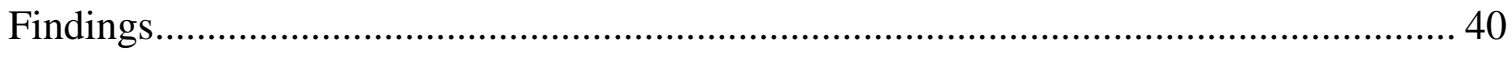

Demographic Information .......................................................................................... 40 


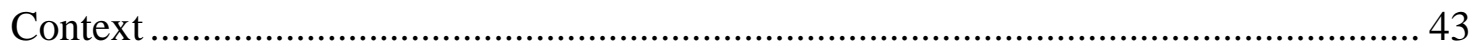

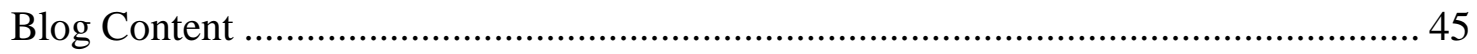

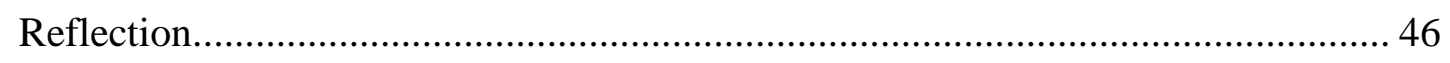

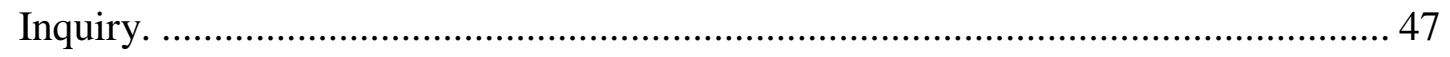

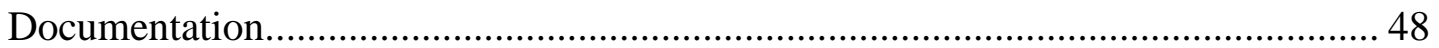

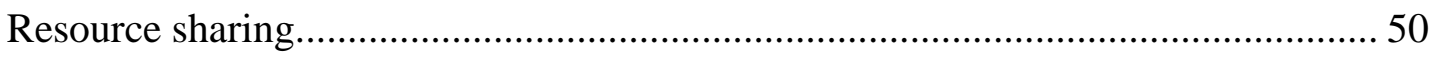

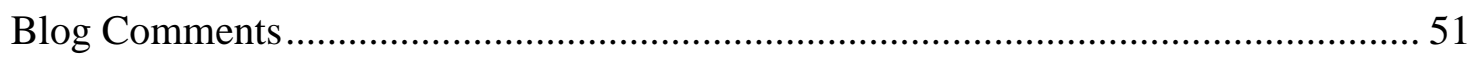

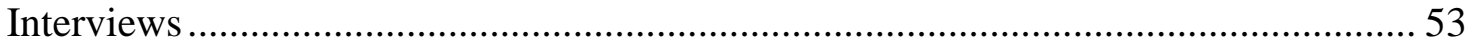

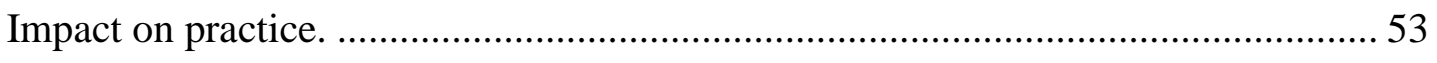

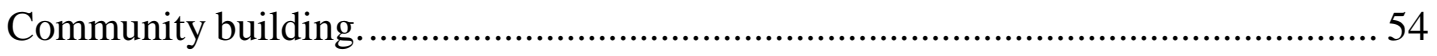

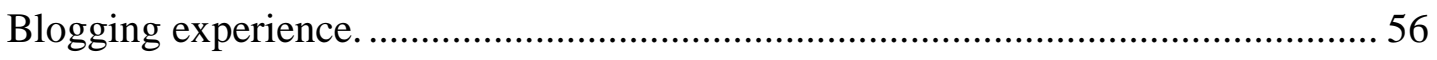

Association between Blog Content and RECE Context........................................... 56

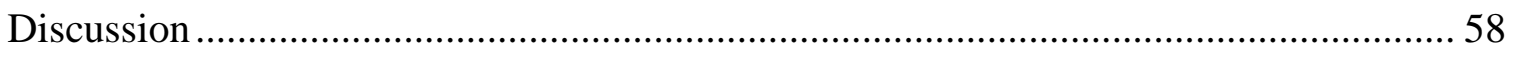

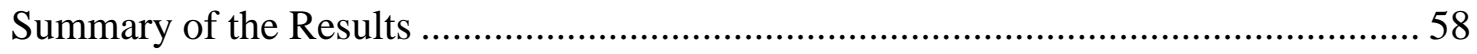

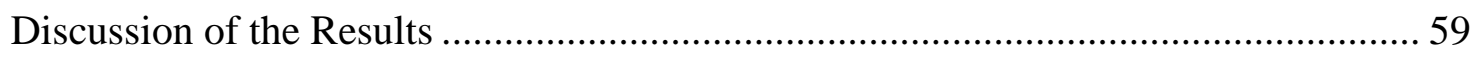

The association between blogging and RECE contexts. ..................................... 59

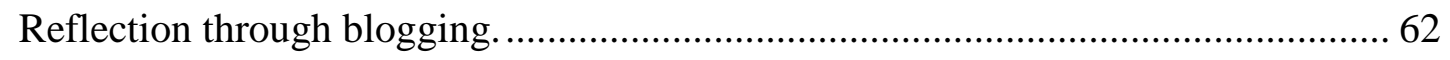

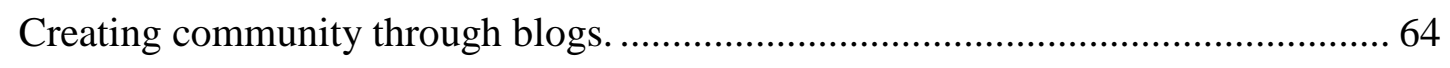

Blogging as a form of continuous professional learning...................................... 65

Implications for Future Research and Practice .....................................................6 67

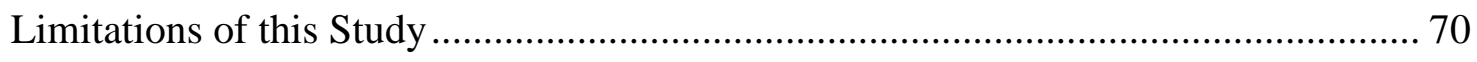

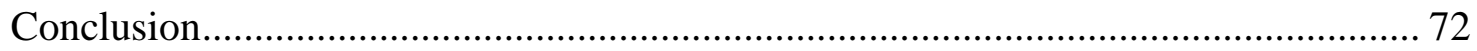

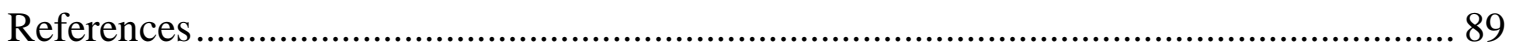




\section{List of Tables}

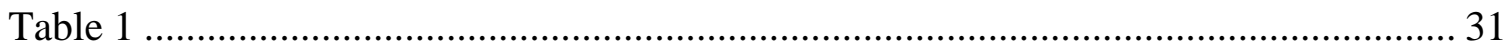

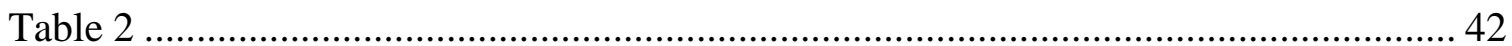




\section{List of Appendices}

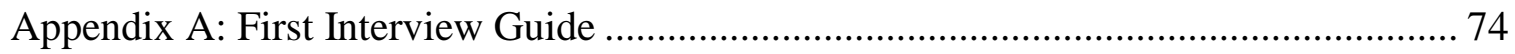

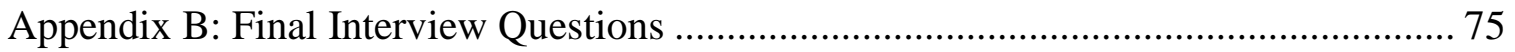

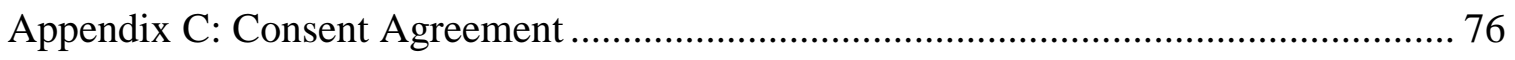

Appendix D: Participants` Blogs Posts by Code ................................................................ 82

Appendix E: Comment Codes by Blog Post.................................................................... 83

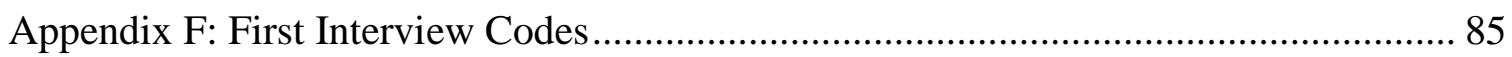




\section{Introduction}

\section{Research Problem}

The availability of the internet and new technologies have created platforms for online learning, as technology has become increasingly important in the personal and professional lives of early childhood educators (ECE) and teaching professionals. Nielsen’s (2012) social media report found that the amount of time the average person in the United States spends on the internet is increasing. The availability of these new forms of technology have allowed early childhood educators to engage in online professional learning opportunities, such as webinars, and post-secondary education programs including certificate, diploma and degree programs. Electronic correspondence and social media platforms, such as Facebook, Twitter, and blogging, have enabled networking opportunities between colleagues to occur across greater distances, allowing ECEs to connect well beyond their geographic region. An examination of the challenges and benefits that the use of technology through blogging, social media, and virtual learning communities, becomes increasingly relevant as these available technologies are becoming more widely used by individuals, larger organizations, and regulatory bodies in the profession of Early Childhood Education and Care (ECEC).

The use of blogs has also continued to grow steadily over recent years, with new blogs being created daily. WordPress, a blogging platform, boasts that their users produce approximately 58.7 million new blog entries each month, with an estimated audience of more than 409 million people across the world reading these blog entries each month (Wordpress.com, 2015). The term "blog” refers to "a Web site that contains online personal reflections, comments, and often hyperlinks provided by the writer” (Merriam-Webster, Incorporated, 2013). Blogging 
provides an opportunity for individuals to share personal or professional experiences, and to exchange ideas and resources. There is a growing community of ECEs, teachers and early childhood professionals using blogs to share their experiences and to connect with others in their profession. The term "virtual learning community" (VLC) refers to these online communities of practice that are formed as ECEs connect through blogs and other social media platforms. Therefore it stands to reason that if ECEs are increasingly turning to online sources for their professional learning, further research is needed to understand the impacts of this type of professional learning on the practices of ECEs.

In Ontario, the College of Early Childhood Educators ("the College") is the professional self-regulatory body for ECEs, the only of its kind in Canada. The Early Childhood Educators Act (2007) defines the practice of Early Childhood Education as "the planning and delivery of inclusive play-based learning and care programs for children in order to promote the well-being and holistic development of children" and mandates that anyone who engages in this practice must be registered with the College. The College further serves the public interest through the establishment of professional requirements for membership in the College, the maintenance of a public register of ECEs, and the establishment and oversight of a Code of Ethics and Standards of Practice for all ECEs (College of Early Childhood Educators, 2011). The Code of Ethics outlines four areas of responsibility which reflect the beliefs and values of Early Childhood Educators: responsibilities to children, to families, to colleagues and to the profession, and to the community and to society. The section on responsibilities to colleagues and to the profession includes the following statement: "Early Childhood Educators value lifelong learning and commit themselves to engaging in continuous professional learning to enhance their practice” (p. $11)$. 
Stemming from this part of the Code of Ethics, in 2014 the College of Early Childhood Educators launched a Continuous Professional Learning (CPL) program. At present, the CPL program is voluntary, however it was developed to become "a regulation which will prescribe ongoing education requirements for members of the College" (College of Early Childhood Educators, 2013b). In the CPL program documents created by the College (2014b), continuous professional learning is defined as "the systemic and intentional maintenance and expansion of the knowledge, skills, and ethical values and behaviours necessary to ensure ongoing quality professional practice” (p. 1). The CPL program further identifies learning through online mediums such as webinars and professional social networking, as well as engagement in virtual learning communities, as examples of continuous learning activities (College of Early Childhood Educators, 2013a; College of Early Childhood Educators, 2014a). The decisions made by the College regarding what types of professional learning to include in the program came out of discussions with professionals from the profession of Early Childhood Education and Care (ECEC) and are in line with studies that have found that the average person is spending more time online using social networking platforms (Nielsen, 2012). Therefore, it stands to reason that if ECEs are already spending time using social networking platforms, harnessing these platforms would be a logical next step in the development of professional learning opportunities.

\section{Purpose of Study}

Through this study I will examine how blogging in virtual learning communities (VLC) can be used as a form of continuous professional learning in the context of Ontario Registered Early Childhood Educators. As I have already established, there is a growing use of internet technology and social media in both the ECEC and broader communities. In Ontario, with the introduction of the CPL program, it is inevitable that the number of professionals using social 
media, such as blogging, to continue their professional learning will also increase. Whereas workshops and conferences often carry a financial cost, for those who have access to the internet through a computer or mobile device, there is no additional cost to blogging or social networking. Having done a literature review of the current body of research with regards to blogging as method of professional learning in ECEC, I have found that, currently, there is limited published research which examines the benefits that ECEs receive through blogging, or the barriers that they face. However, several studies in the field of education have found indications that blogging can serve as a form of professional learning (Harland \& Wondra, 2011; Killeavy \& Moloney, 2010; Lin \& Yuan, 2006; Lindgren, 2012; Luehmann, 2008; Robertson, 2011; Stiler \& Philleo, 2003; Yang, 2009).

I chose to examine the use of blogging as a form of professional learning because of the introduction of the CPL program in Ontario. As early childhood education is now a publicly regulated profession, and registered members may be engaging in professional learning through blogging, I believe that an examination of how that blogging will impact their practice through their motivations and actions would be significant for both the profession of ECEC and the public, which is served by the College. The inclusion of professional social networking and participation in virtual learning communities as continuous professional learning activities was based on focus groups, rather than formal research. Through this study, the content of participants' professional blogs and their comments on other blogs were studied, with a focus on evidence of professional growth. I was guided by the following research questions: (a) what do RECEs blog about? (b) in what ways do RECEs engage in reflection through blogging? (c) in what ways do RECE engage with each other through blogging? and (d) in what ways does blogging influence the daily practice of RECEs? Additionally, through interviews, participants 
were asked about their experiences writing a professional blog and engaging in a virtual learning community. The intention, through both aspects of this study, was to determine whether blogging and engagement in a virtual learning community could be validated as forms of professional learning.

\section{Research Paradigms}

Through this study I sought to examine both the self-perceptions and practical experiences of RECEs and therefore I structured my research methodology using a social constructivist (interpretivist) paradigm. Creswell (2014) defines social constructivism as a belief that participants construct their own meaning as they try to understand the world in which they live and work. A social constructivist approach allowed for a deeper exploration of the context in which the participants exist and allowed for the participants to guide the research and generate themes. I chose to use this paradigm as it fit best with my interest in inductive research, as it allowed for the generation of theory with regards to the professional impact of the creation and maintenance of a professional blog, and also because it fit with the social nature of blogging. My intention through this study was not to prove or disprove my own ideas and theories about blogging in the context of a virtual learning community. Rather, my intention was to develop an understanding of how RECEs make use of blogging as a medium for professional learning, and to determine if participants' perceptions of their blogging were in line with their actual use of the medium. A social constructivist paradigm allowed me to conduct research with the understanding that reality and, by extension, research is socially constructed (Willis, 2007). Participants in this study were considered co-constructors of knowledge, and actively involved in the research. As such, just as it was important for me to reflect on my own context and how that could shape my interpretations of the data, it was also essential to gather data on each 
participant's professional context, to understand how it may shape their experiences and perceptions. Social constructivists place high value on the reflections of experienced practitioners to generate knowledge and gain understanding, making this the most logical paradigm to use in my study of professional learning (Willis, 2007).

\section{Social Location}

An awareness of my own context and potential biases in this area of research re-enforced the need to conduct this study using a social constructivist paradigm, as social constructivism allows for a certain amount of subjectivity, placing the research emphasis on context and understanding (Willis, 2007). I believe that this awareness of my own context has supported me to connect with the participants in my study and to better understand their professional contexts. It has also allowed me to filter my interpretations of the data through our shared contexts as RECEs, as well as to separate my own experiences from theirs, in order to examine the data from both individual and shared contexts.

I am a Registered Early Childhood Educator currently practicing in the province of Ontario. I have worked in a variety of ECEC settings, including licensed child care, family support programs, an early intervention program, and as a field visitor and faculty member for an early childhood education diploma program. Additionally, I have facilitated professional learning opportunities through the facilitation of workshops in partnership with local and provincial ECEC organizations. I conduct this research with an understanding that my own experiences working as an RECE and my own views of the benefits of professional learning have influenced the design of this study and have likely influence my interpretation of the data as well.

It is also important to note that for several years I have maintained a professional blog and linked social media accounts through canadianece.ca. My use of social media platforms, 
such as Twitter and Pinterest, is almost exclusively related to my own professional interests and a desire to continue to learn and grow as an RECE. For the past decade I have engaged in professional learning through online mediums, initially through email-based groups which provided a forum for discussion with other educators, and then after discovering several educator-penned blogs, I was inspired to create my own blog where I could share some of my own experiences as an educator. My own professional growth through writing a blog, and engaging with virtual learning communities, is the reason why I am interested in examining blogging as a form of professional learning. It has also informed my interpretation of the data, as I have firsthand experience with both the benefits and challenges of maintaining a professional blog.

\section{Conceptual Framework and Literature Review}

Within a social constructivist paradigm, this study used a conceptual framework, with key theories and ideas incorporated from each individual concept. The study was framed in this way to examine in depth each of the three main concepts: professional learning, communities of practice, and technology. Although each of these concepts were treated as independent and unique, the design of this study brought them together, allowing for an examination of how these concepts intersect and work together.

\section{Professional Learning}

The concept of professional learning is one that is constantly in flux. As time passes, and new ideas and technologies emerge, our concept of professional learning, or at least how professional learning comes about, changes and evolves. As such, as I began this study it was necessary to ask the question "what is professional learning?” It should first be noted that the 
term "professional learning” is sometimes used interchangeably with the term "professional development”. In recent years the research seems to have favoured the former, however these two terms may not have the same meaning. Fleet and Patterson (2009) suggest that one challenge with the use of the term "professional development" is that it presumes that there is a continuum upon which an educator can move from being less to more professional. I also found that some conceptualizations of professional learning focused on outcomes for children or programs, including the College’s definition: "the systemic and intentional maintenance and expansion of the knowledge, skills, and ethical values and behaviours necessary to ensure ongoing quality professional practice” (p. 1). Alternately, the AECEO’s (2014) definition focuses on the educator, defining professional learning as "a range of on-going activities in which early childhood educators are actively engaged in the processes of assessing and reflecting on their own learning and practice” (para. 13).

Although I found many similarities between each conceptualization of professional learning, what was most significant was the idea that professional learning needs to be addressed in the context of each ECE, based on their own unique interests and needs (Edwards \& Nuttall, 2009; Lehrer, 2013; OECD, 2012; Opfer \& Pedder, 2011; Shore, 2012). There is a significant amount of literature that focused on specific forms of professional learning (such as workshops, mentoring programs, environment-based training, and online learning), and their efficacy, and little that took a broader view of professional learning within an ECEs ongoing practice. In light of this, Opfer and Pedder (2011) reconceptualised educator learning as a complex system, rather than an event, noting that there are various social dynamics at work, which combine and interact in many ways. Opfer and Pedder identified and examining three overlapping systems: the individual educator, the school/program, and professional practices (which would include 
specific strategies and activities). This is similar to Oberhuemer (2005) who identified four levels of activity which contributed to professionalism in ECE: (1) interacting with children, (2) centre management and leadership, (3) partnerships with families, and (4) professional knowledge base. Oberhuemer argued that all four of these levels needed to be addressed as areas for professional learning.

Recognizing that there are many areas for professional growth, we can bring this back to Opfer and Pedder’s (2011) conceptualization of educator learning as a complex system, acknowledging that each educator will have their own unique learning needs, and begin to move away from looking only at isolated professional learning. Shore (2012) posited that the "one size fits all” approach to professional learning is ineffective because it stems from an incorrect assumption that all educators are ready and willing to change. The College’s CPL program seems to operate on the same principles identified here, allowing educators to set their own goals, and choose from a variety of professional learning activities which would support them to meet their goals (College of Early Childhood Educators, 2013a; College of Early Childhood Educators, 2014b). It is through this conceptualization of professional learning, that I examined the practice of professional blogging.

\section{Reflective practice.}

One aspect of professional learning which needed to be addressed in the context of this

study was the concept of reflective practice. In the profession of ECEC and broader profession of education, there seems to exist a fundamental assumption that reflection is an essential element of professional learning, and much of the literature on professional learning addressed reflection as such (AECEO, 2014; Alvestad \& Röthle, 2007; Cherrington \& Thornton, 2013; Lehrer, 2013; Oberhuemer, 2005; Recchia \& Beck, 2014; Wood \& Bennett, 2000). The early years 
pedagogical document “How Does Learning Happen?” (HDLH) released by the Ontario Ministry of Education stated that "[e]ducators are reflective practitioners... [who] consider their own practices and approaches and the impacts they have on children, families, and others” (Queen's Printer for Ontario, 2015, p. 19). In HDLH, critical reflection was identified as the basis for the delivery of high-quality early years programs, through which educators "test long-standing views and taken-for-granted practices and consider new approaches and ways of thinking about their work” (p. 20). Even the College (2014a) emphasized reflective practice as an important element of continuous professional learning, stating that it "helps RECEs continue to align what they actually do each day as professionals with the values they hold” (p. 1). As this study asked participants to blog about their everyday practices, it was important to address the concept of reflective practice, both during the construction of this study, and then again, once examples of reflection were found during the data analysis portion of the study.

John Dewey was among the first to write about reflective thinking, which became the foundation upon which the concept of reflective practice was built. Dewey (1910) made the distinction that reflective thought deliberately seeks the basis for a belief and examines the capability of supporting that belief. Dewey also posited that language is an essential tool for thinking, in particular reflective thinking, which makes a written practice, such as blogging, a logical way to encourage reflective thought. Rodgers (2002) took Dewey’s writing and identified four criteria for Dewey's concept of reflection. These criteria have served as a guideline for understanding reflective practice through this study. The criteria are (1) reflection creates meaning for the learner as they deepen their understanding through experiences, (2) reflection is a systemic and disciplined process, (3) reflection must happen in the context of the community and (4) it requires a mindset which values personal and intellectual growth (Rodgers, 2002). 
These four criteria were used in each element of the research design. The idea that reflection creates meaning and can be an agent of change was the basis upon which this study was designed. This idea influenced the study design to examine not only the content of individual blog posts and comments but also to include interviews where participants were asked to further reflect on their experiences within the study. An understanding of reflection as a systemic process is the reason why participants were asked to commit to writing one blog post per week for the duration of the four month study. Similarly the criteria of reflection occurring within the context of community necessitated a similar structure in the research design, whereby participants were also asked to read and comment on at least one other blog post per week. Lastly, the criterion that reflection requires a mindset which values personal and professional growth was met through the recruitment process, as it was assumed that only those who were interested in professional development volunteered to participate in the study.

Donald Schön’s theory of reflection-in-action was also fundamental to this study. Schön (1983) argued that the process which he called reflection-in-action was key for practitioners as they encountered challenges or uncertainties within their practice. Schön differentiated reflection-in-action from knowledge-in-action, noting that the latter was simply "the characteristic mode of ordinary practical knowledge” (p.54). The process that Schön proposes refers to the situations that practitioners deal with which require a greater amount of thought and intentionality. He states that "reflection tends to focus interactively on the outcomes of the action, the action itself, and the intuitive knowing implicit in the action” (p. 56). What I found to be especially relevant to the profession of ECEC was the idea that because an individual's practice can become repetitive, as they complete similar interactions, tasks or routines, they may be drawn into patterns of behaviour that are not easily changed. Schön referred to this as "over- 
learning”, and argued that these over-learned practices could be corrected through reflection, as reflection offers an opportunity to deconstruct and even criticize practices and to make new sense of situations. Schön’s theories fit naturally into the social constructivist framework of this study, as he believed that "when someone reflects-in-action, he becomes a researcher in the practice context” (p. 68). Through the blogs and interviews, I sought to provide opportunities for participants to reflect on their own practice and also to be co-researchers, with opportunities for them to generate their own ideas and theories alongside my own. I also hoped that by providing opportunities for participants to reflect-on-action, this would also increase their ability to reflectin-action through their daily practice.

\section{Blogging as reflective practice.}

A review of the literature related to blogging also found the concept of reflective practice to be a recurring theme. Most of the studies which specifically addressed blogging as a form of reflective or critical thinking were done at post-secondary educational institutions, most likely because of the structured format and the researchers' ability to control participation in the process by incorporating the blog into the course syllabus (Harland \& Wondra, 2011; Lin \& Yuan, 2006; Shoffner, 2009; Stiler \& Philleo, 2003).

Stiler and Philleo (2003) compared students' reflective writing through paper assignments and blogging. Students from two undergraduate pre-service teaching courses at a University in the United States were asked to complete a reflective journal and supported to do so by using Blogger, a blogging platform, over the course of the semester. These reflections were compared with paper reflective assignments from a previous semester and the authors found that students' blog entries were more analytic 
than the paper assignments had been. Additionally, a student survey was completed to evaluate the students' experiences using Blogger and the authors found that more than half of the students were at least somewhat satisfied with the experience and would recommend it for future use. However, concerns were raised regarding the issue of privacy and challenges with regards to the students' understanding and comfort level with technology. Another key finding was that guidance and mediation on the part of the instructor was found to be critical for students' success (Stiler \& Philleo, 2003). The results of this study seem to indicate that an online medium supports reflective practice amongst students, but also indicates that support is needed in the use of the blogging platform. It should be noted that this study was cited frequently in other literature gathered during this review and seems to have formed the basis for numerous other studies which examine the impact of blogging on pre-service teachers and other professionals in terms of their professional learning and participation in community.

Lin and Yuan (2006) found that students had a generally positive response with regards to their learning through blogging. Students enrolled in an Automation Engineering program at a Taiwanese college were asked to complete a weekly learning reflections blog entry and to provide feedback on their peers' entries over the course of 18 weeks. Data were collected through the blog entries and comments, student completed questionnaires at midterm, and assessments of the students learning through tests and assignments, completed at midterm and upon completion of the course. The results of the students' learning assessments found a positive correlation between the students' learning performance, which consisted of an assessment of their test scores, homework assignments and their reflections, and the number of entries they posted on their blogs. 
The authors posited that the students who had higher performance academically were also those who took more time to reflect on their learning. The student questionnaire responses indicated that most students felt that both using the learning reflections blog and reading the blogs of their peers had a positive impact on their learning. Overall, the findings of this study seem to indicate that students perceived the use of a blog as a reflective tool as helpful, regardless of whether this had a direct impact on their measurable learning. It is also interesting to note that although the students seemed to put a high value on comments from their peers, the researchers noted that they seldom made comments on their peers' reflections (Lin \& Yuan, 2006). Although the authors of the study indicated that their findings supported the use of the learning reflections blogs, based on the data, it seems just as likely that the students who made the most use of the blogs, were those who were already at a higher level academically. Further study would be needed to determine whether reading and writing learning reflection blogs would increase the learning performance of all students, including those who have been evaluated at a lower academic level.

Harland and Wondra (2011) developed the Four Levels of Reflection for Teacher Education assessment tool in order to examine the levels of reflection shown in the students' writing, through paper reflections and blog entries. The four levels were identified as: Nonreflection (Descriptive), Understanding, Reflection and Critical Reflection. Nonreflection indicates writing that describes course content or clinical experiences without evidence of trying to understand it. Understanding describes writing which includes evidence of connections being made between what has been learned and observed, without analysis of how this understanding would translate into practice. 
Reflection includes evidence that course content and clinical experiences are being used to shape teaching philosophy and future practice. Finally, Critical Reflection describes writing which "critically reviews assumptions, and a new conceptual framework is formed” (Harland \& Wondra, 2011, p. 133). Participants in this study were students at Illinois State University who were undergraduate education majors. The authors found that students who wrote blog entries were significantly more reflective than those who wrote paper reflections; however, neither set of students achieved the highest level of reflection, critical reflection (Harland \& Wondra, 2011). Harland and Wondra's results are in line with Stiler and Philleo (2003), as both studies showed deeper reflection and analysis through blog entries rather than paper reflections. Although it seems that an online medium for engaging in reflective writing does support deeper reflections, Harland and Wondra's (2011) findings show that these reflections still fall short of the desired level of critical reflection indicating that students may need further support to move to the fourth level of reflection. Both this article and Stiler and Philleo (2003) seem to indicate the need for feedback and community in order for blogging to be a successful form of reflective practice.

\section{Communities of Practice}

Another important concept for this study is communities of practice. The term "communities of practice" (CoP) originated with Etienne Wenger, who identified people as an organizations most valuable resource. Wenger (1998) theorized that "communities of practice develop around things that matter to people” (p. 2). He further posited that communities of practice defined themselves through three dimensions: (1) joint enterprise, (2) mutual engagement, and (3) shared repertoire. Different than networks or 
teams, communities of practice develop based on the interests and needs of their members, producing a shared practice. They reflect the members own understandings of what is important. Even when the community of practice ceases to be actively engaged, those who have had membership in the community continue to be impacted by their participation, through the knowledge and experience they gained. Wenger suggested that communities of practice fulfill four functions: (1) allow for the exchange and interpretation of information, (2) retain knowledge, (3) steward competencies, and (4) provide homes for identities (Wenger, 1998). These communities provide opportunities for individuals to share their own knowledge, and to learn from each other as they continue to grow in their individual practice, as well as within the shared practice created by the community.

\section{Virtual learning communities.}

Several studies looked specifically at virtual learning communities. Sobrero (2008) examined communities of practice by comparing virtual and co-located communities. She found that while co-located CoP were most likely small, with a closed membership, virtual communities could be dispersed geographically with a more diverse group and an open membership. Members of virtual learning communities were also less likely to know each other prior to their inclusion in the CoP (Sobrero, 2008). Previous literature has also identified criteria necessary for successful virtual learning communities including: the negotiation of a mutually beneficial enterprise, reliable technology, building trust and respect through social engagement, the maintenance of strong leadership and momentum, active participation, relevance of topic, a supportive environment, and member benefits (Byington, 2011; Sobrero, 2008). This research seems 
to confirm the need for communities of practice to continue to evolve based on the needs of the members, as Wenger had suggested.

\section{Development of learning communities.}

Research done in the profession of education has examined the development of learning communities through online mediums, by establishing a link between instructor feedback and students’ learning and reflection through their blog entries (Harland \& Wondra, 2011; Stiler \& Philleo, 2003). Other studies have looked at the development of learning communities through online mediums such as blogs (Killeavy \& Moloney, 2010; Lindgren, 2012; Luehmann, 2008; Luehmann \& Tinelli, 2008; Stavrositu \& Sundar, 2012; Yang, 2009).

Luehmann (2008) completed a case study of Ms. Frizzle, a white, middle-class science teacher, who was already an established blogger at the time of the study. The author used data collected from a year's worth of blog entries, comments from a four month period, emails between the author and Ms. Frizzle, and phone interviews with two of Ms. Frizzle’s colleagues. Luehmann posited that Ms. Frizzle’s regular entries on her blog and the comments/feedback from the blogging community allowed her to validate and refine her teaching practice. The examination of the types of work that Ms. Frizzle was conducting through her blog found that most of it was related to building community through mentoring and resource sharing, which was further bolstered by the blogging community that Ms. Frizzle had established who regularly read and commented on her entries. Luehmann further posited that although the examination of the data did not provide direct evidence of professional growth, the richness and regularity of the blog entries were indicative of growth. She stated that through these posts, Ms. Frizzle 
engaged in several teacher learning practices that have previously been identified in literature (Luehmann, 2008). It stands to reason, given Ms. Frizzle’s regular and continued use of her blog that in this instance, blogging has been a supportive experience in her professional life. Also, the connections that she has made through her blog seem to benefit all parties involved, lending validity to blogging and online communities of practice as a form of professional growth and development. Further assessment of the blogging community through questionnaires or interviews would generate further insight on the effect of a reflective blog on the larger blogging community.

Killeavy and Moloney (2010) sought to examine how reflecting in a social space, such as a blog, could create a learning community amongst beginning teachers. They followed two groups of newly qualified secondary school teachers in Ireland, all of whom were asked to create and maintain blogs over a four month period. The researchers also created and maintained a project blog for all participants, which was used to encourage participation and reflection. They found that the participants used their blogs infrequently and rarely as a reflective journal. The researchers did not find evidence that use of the blog led to further reflection or created a learning community. Based on the feedback of participants, there was some indication that reviewing old entries supported some reflection. The predominant reasons that participants gave for not using the blogs were lack of time and lack of privacy (Killeavy \& Moloney, 2010). This study's findings identified some of the same barriers to success as other studies (Shoffner, 2009; Stiler \& Philleo, 2003). As these were teachers in their first year of practice, they seemed overwhelmed adjusting to their new positions and therefore unable to put forth the time and effort into blogging. This study may have had different results if participants had 
time to settle into their new positions prior to taking on the added responsibility of blogging.

Luehmann and Tinelli (2008) examined the relationship between social networking and professional learning and development through the act of blogging. Fifteen practicing secondary school science teachers in the United States, who were enrolled in a graduate level seminar class, were asked to maintain a blog as well as to read and respond to the entries of their peers. The data that was collected included the contents of the blog entries and comments as well as the participant responses to a survey. The blog entries and comments were coded and classified within three categories, cognitive work, affective work and social work; most of the comments were found to be related to social work. Luehmann and Tinelli posited that the high level of comments was indicative of participants learning through their interactions, making reference to the depth and richness of the interactions within these comments (Luehmann \& Tinelli, 2008). Although the authors of this study have identified that learning occurs through the interactions, further study is needed to examine how these interactions support continued learning and professional development, which could include either qualitative or quantitative assessments of participants knowledge and self-efficacy prior to and after engaging in reflective practice through blogging and an online community.

Lindgren (2012) recognized the effect of online communication in building community. Over the course of four months, Lindgren followed nine blogs written by Swedish preschool teachers attending a University level course on pedagogical documentation. Although the intent of the study was to examine the ethical considerations as they related to documenting children, the process by which the 
preschool teachers reflected and connected through their blogs is equally important. Lindgren found that the participants regularly commented on each other posts, adding their own ideas and extending the discourse (Lindgren, 2012). This study showed how an online community could extend learning and professional discussions beyond face to face discourse. Through blog entries and comments, participants were able to reflect on their own ideas, share their experiences with others and provoke further reflection and critical thinking in their peers. This article could also indicate that learning communities are best formed through common interests and motivated by the needs of the users, which is in line with previous findings (Luehmann, 2008; Luehmann \& Tinelli, 2008; Yang, 2009) and with Wenger’s (1998) theory about communities of practice.

\section{Technology}

Examining technology as a concept can prove difficult as many pre-existing conceptualizations focus selectively on certain aspects of technology, rather than taking a more holistic view (Orlikowski, 1992). I found that even dictionary definitions of the word seem to limit the concept of technology to the applied sciences. The most inclusive definition I found defined technology as "the branch of knowledge that deals with the creation and use of technical means and their interrelation with life, society, and the environment", with a secondary definition being "the application of this knowledge for practical ends” (Dictionary.com Unabridged, 2015). Orlikowski (1992) proposed a structural model of technology which posits that technology is interpretively flexible, and that there is a duality inherent in technology, as it is both the product of human action but also assumes its own structural properties. Orlikowski identifies three components within the structural model of technology: human agents, material technological artifacts, and 
institutional properties of organizations (ideology, culture, etc.). Of most relevance to this study is the premise that technology is a medium of human action, which can both constrain and enable the user. Orlikowski states "[i]n using a technology, users interpret, appropriate, and manipulate it in various ways, being influenced by a number of individual and social factors” (p. 403). For the purposes of this study, the RECEs are the human agents, blogging is the material technological artifact, and the profession of ECEC would be the institution. Therefore through this study, this conceptualization of technology can be used to examine how RECEs use blogging in the context of their professional practices.

\section{Advantages and disadvantages of blogs.}

Several studies examined the benefits and challenges of using blogging as a medium for communication and professional learning. Powell and McCauley (2012) examined blogs as a medium to create and nurture partnerships between parents and educators. They found that the use of blogs supported the educators to recognize children's interests, to monitor and document children's progress, and to be more analytical and reflective. They also found that the blogs were an effective medium for provide information to parents and increasing two way communication between parents and educators (Powell \& McCauley, 2012). McDaniel, Coyne, and Holmes (2012) found that new mothers who blogged reported increased feelings of connectedness and well being, and had higher perceptions of social support. Byington (2011) studied blogs in the context of communities of practice and found both advantages and disadvantages to the medium. Ease of use and convenience were two advantages to the blogging medium, as was the fact that blogs are accessible from many different devices and keep a historical 
record of posted content. Advantages specific to the use of blogs within communities of practice included the opportunity to exchange ideas, experiences and knowledge, to reflect, and to receive multiple perspectives through comments and other forms of response. Byington (2011) also found a number of disadvantages to blogging as a medium, including challenges with technology, lack of motivation, and the possibility that incorrect information may be passed on.

\section{Motivation towards blogging.}

Another theme underlying much of the literature regarding the use of blogging is the motivation of the individual to maintain their blog. Much of the research conducted to date seems to validate the idea that an individual's motivation towards blog use influences their ability to use a blog as a medium for professional learning (Killeavy \& Moloney, 2010; Lin \& Yuan, 2006; Lindgren, 2012; Luehmann, 2008; Shoffner, 2009; Yang, 2009).

Yang (2009) studied the use of a reflective blog with pre-service teachers in an English as a Foreign Language (EFL) training program in Taiwan. Students were initially introduced to the concepts of critical thinking and reflection and were then asked to complete an online reflection after each class. The data collected included the blog entries and comments, group reflective dialogues and the end of semester questionnaire. The blog entries were coded and categorized, and researchers found that the entries were more descriptive than critical overall. The instructors in the courses responded to the students' entries did seem to challenge and deepen the reflections, in line with previous findings, as there was a measurable increase in posts where the instructors responded and challenged the participants thinking, than when the instructors did not engage (Stiler \& Philleo, 
2003; Yang, 2009). Continued feedback and external motivation may be needed for individuals to continue to engage in reflection, validating both the importance of the role of motivation and community with regards to blogging as a medium for reflective practice.

Shoffner (2009) asked nine pre-service teachers enrolled in a Masters program to establish and maintain a blog over the course of eight months. Focus groups and interviews were also conducted to gather additional data. The responses from participants were highly variable with few making regular use of the blog and the number of blog entries dropping significantly over the course of the eight months. Through the focus group, Shoffner found that although the participants had positive attitudes towards the idea of reflection, classifying it as a necessary part of their own teaching practice; they had specific ideas about how that reflection should be experienced. Participants stated that reflection should be easy and provide connection to others, which was something they did not experience over the course of this study (Shoffner, 2009). This seems to indicate that unless the individual is self-motivated towards reflective practice and blogging, then they will not receive any benefits from participating in the process or will decline to participate entirely. This is in line with other studies, which similarly indicated that motivation was significant factor in the use of blogging as medium for reflective practice and/or professional learning (Killeavy \& Moloney, 2010; Lin \& Yuan, 2006; Lindgren, 2012; Luehmann, 2008; Shoffner, 2009; Yang, 2009).

\section{Conclusion}

While each of the studies discussed here provides some insight into the various aspects of blogging as a form of continuous professional learning, there are some studies 
which are more relevant to my study than others. There were several studies which addressed the use of blogging as a medium for learning and reflection in an academic context. However the findings from these studies, while insightful into the use of blogging as a medium for reflection, do not sufficiently address the needs and motivations of educators in practice. Instead, I found that the studies which specifically addressed how educators made use of blogging in their daily practice to be more relevant to this study. In particular, Luehmann's (2009) case study, which examined one participant's professional learning through her use of blogging, as well as her engagement with those who read her blog providedinsight into the use of blogging as a form of professional learning. In addition the studies which followed groups of educators who engaged in learning communities through blogging were beneficial in understanding the role of the community in supporting professional learning through blogging (Killeavy \& Moloney, 2010; Lindgren, 2012; Luehmann \& Tinelli, 2008). As these studies addressed the experiences and challenges, of practicing educators in their use of the blogging medium, they were the most useful in both the shaping of this study and in the analysis of my findings.

\section{Methodology}

\section{Approach}

There were a number of factors that were considered prior to my decision to use a qualitative approach. First, my interest was not in simply measuring RECEs' levels of reflection or the quantity of their blog posts and comments in order to examine blogging as a medium for reflective practice or professional learning. Rather I sought to understand the experiences of 
RECEs as they integrated blogging into their existing practice. By using a qualitative approach, I was able to examine the experience of blogging through the stories and perceptions of the participants themselves. This allowed for the generation of theories with regards to what aspects, if any, of the blogging process support increased reflection or changes in practice and allowed me to use inductive methods to organize the data. A qualitative approach was also more conducive to using multiple sources of participant-generated data, which consisted of the blog entries and comments collected over a period of four months, as well as two sets of participant interviews which occurred at the one and four month intervals. A qualitative approach was most in line with the social constructivist paradigm, which seeks to understand the context and meanings generated by the participants, rather than imposing those of the researcher (Creswell, 2014). Finally, a qualitative study allowed for a more holistic examination of the data and the context in which the data was generated, which was essential because of the diverse experiences of the RECEs who participated in this study, as well as the challenges that arose through the use of the blogging medium. This study was designed to examine in detail the perspectives of RECEs through their experiences of blogging, and online community.

\section{Strategy}

As my intention through this research study was to generate theories regarding the use of blogging as a method of continuous professional learning for RECEs, I chose to use grounded theory as my research strategy. Creswell (2014) explained grounded theory as a research design which allows the researcher to base their generated theories in the views of the study participants. Through the paradigm of social constructivism, this seemed to be the most appropriate strategy for this study, as I was more interested in generating new theories based on the participant's experiences of using the blog, rather than trying to develop theories based on 
previous research, of which there was little, or my own experiences with blogging. Although the discussion of the data was informed by the existing literature, particularly with regards to the concept of reflection, as well as my own experiences, the focus of the generated theories is grounded in the experiences of the participants, as understood through their blog posts and interviews. Furthermore, grounded theory is a multi-stage process through which data are gathered and analyzed, and then used to inform further data collection and analysis as theories begin to be generated (Oktay, 2012). This informed the data collection methodology, as the decision was made to complete interviews and collect blog data at two intervals. The first set of interviews and data collection occurred approximately one month into the study, and the final set of interviews and data collection were completed at the end of the four month study. This allowed me to alter the interview guide based on the data collected from the blogs and blog comments, using this data as a determinant of significant themes to be explored. Within the grounded theory strategy, I used a constant comparative method, which will allow me to compare the data gathered from each of the participants and use that to develop concepts, and later, generate theory (Oktay, 2012). It was important to use grounded theory, as there seemed to be a limited research base from which to draw to examine blogging as a medium for professional learning for RECEs, and therefore these theories needed to be generated from the participants in the study themselves.

\section{Scope}

The scope of this study was limited to a small group of self-identified Registered Early Childhood Educators practicing in Ontario and did not include their co-workers, other RECEs or the families of the children in the programs. It was limited to a four month period of time during which participants were asked to blog on a weekly basis, and to comment on at least one other 
blog post from the study each week. Data was gathered from the content of blog posts and accompanying comments which were written by the participants. Data from other forms of online discourse such as social media accounts, or email correspondence were not included. The reason for this was to keep the focus of the research on the RECEs and their use of blogging as a form of professional learning, both individually and in the context of a virtual learning community. For this reason, the results of the study were not extrapolated beyond the profession of early childhood education or to families or other professionals working in ECEC settings.

\section{Sample and Recruitment}

The proposed sample for this study was six to ten RECEs practicing in Ontario, and the final sample was nine RECEs. The reason for the small sample size was due to the amount of data that was likely to be generated through weekly blog posts, comments and two semistructured individual interviews. Keeping the sample size small allowed for a more in depth examination of the data and of the individual stories and ideas generated by the participants in the brief period of time allotted for a Masters research paper. Participation was voluntary, with no financial or other compensation, and was limited to participants currently practicing in the profession of ECEC in Ontario who are registered with the College of Early Childhood Educators ("the College"). Registration with the College was not verified through the public register, instead I relied on participants to self-identify as Registered early childhood educators. My reason for this, in consultation with the Ryerson Ethics board, stemmed from the fact that ECE is a protected title, which obligated me to report them to the College if they falsely identified themselves as RECEs. Although this allowed for the possibility that participants were not, in fact, RECEs, it reduced the risk to participants and was not considered to be detrimental to the findings of the study. 
Participants were solicited through an ad in the e-bulletin of the Association for Early Childhood Educators Ontario (AECEO), as well as through my professional Twitter account (@canadianece). Although, I did not post the flyer on my own personal Facebook page, I did post the flyer on the Facebook group for the 2013/2014 and 2014/2015 MA in ECS groups, asking those with connections in the ECEC profession to pass the flyer on to their networks. The reason for these methods of recruitment was convenience, as I was already a part of an online ECEC community through my social media accounts and had a connection to the AECEO, as a member and through a past internship at their head office. I further chose to use only my professional contacts and not my personal contacts, in order to eliminate any bias or potential for coercion. It should also be noted that the use of these recruitment strategies may have lead to a sample that were more likely to be motivated towards professional growth and who were more likely to have previous experiences with blogging or online technology. However, this may have supported one of Dewey's four criteria for reflection, as established by Rodgers (2002), which is that reflection requires a mindset which values personal and intellectual growth. Those who volunteered to participate in this study and committed to a weekly practice of blogging have likely done so to support their own professional learning. Through the flyer, interested participants were asked to contact me via email. Prior to their confirmation as participants in the study, they were made aware of the ethical considerations of their participation through the consent form, including an agreement to post on a public blog, as well as the potential that the findings from this study may be published. A signed consent form was completed and submitted by all participants. Additionally, all participants were advised that they are personally responsible to ensure that the content they publish on their blog is content which they have permission to make public. 
There were twelve respondents who expressed their interest, through email, in participating in the study. However, two of the participants were deemed ineligible, as I knew them both personally and did not want to risk the possibility of further research bias, whether actual or perceived. Through email, I responded to any questions that the remaining ten respondents had posed about the expectations and ethical considerations of the study and then sent each of them the consent form. Nine respondents sent back the signed and completed form, while the tenth replied to state they were no longer able to participate in the study. The remaining nine respondents, henceforth referred to as “participants”, were provided with instructions related to the creation of their professional blog and were asked to respond with the following information prior to the start date of the study (March 1, 2015): their level of education, their preferred email address, their blog url, and their chosen pseudonym(s).

\section{Setting}

Blogging is an online medium which allowed participants to write their blog posts in a physical location which was convenient for them. This was considered to be a natural setting. Participants used WordPress which is a free, web-based blogging platform. WordPress was chosen because it is cost-free and designed to be used by both novice bloggers and those with skills related to web development. It is web-based, meaning that participants were able to use any computer to create blog posts, and is also available as an application on mobile devices, such as tablets and smart phones. Wordpress was chosen over other similar blogging platforms based on my own experience with it, as this allowed me to support participants through any difficulties encountered related to the use of the technology. The setting for the interviews which occurred after the first four to six weeks of the study, and again at the conclusion of the four month study, varied based on the location of the individual participants. Most of the first interviews were 
completed over the telephone. The only interview which occurred in person took place at a public library, chosen by the participant. Conducting the interviews by telephone or in a public space was done for convenience as well as to ensure the privacy and comfort of both the participants and myself, as the researcher. For the final round of interviews, several participants chose to complete the final interview by email, as it was indicated to be more convenient. The interviews will be further discussed in the subsequent data collection section.

\section{Data Collection}

There are two main sources of data that were collected during this study, the participants’ blog entries, including comments, and two sets of individual participant interviews. As part of the study, the participants were asked to create a blog using the WordPress platform and to commit to writing a minimum of one blog post per week related to their practice as an RECE over the course of four months. This supported Dewey's criteria for reflection, as identified by Rodgers (2002), which is that reflection is systemic and disciplined. There were no set topics for the blog posts, as I wanted to support participants to construct their own meaning and to examine their own experiences, as part of a social constructivist approach. Participants were also provided with the URLs of the other blogs in the study and asked to read and comment on at least one blog post per week. The decision to have participants engage with one another's blogs throughout this study was to support co-construction of meaning, as well as to support the development of community through mutual engagement (Wenger, 1998). The creation of a virtual learning community, through the reading and commenting on of blog entries, also supports the criteria that reflection must occur in community (Rodgers, 2002). The blog entries and comments made by participants in the study were collected for content analysis. In order to further protect the privacy of participants, who blogged under a pseudonym of their choice, each participant was 
given another pseudonym (different than what was used on their blog) which is how all the data has been organized. Furthermore at the completion of the study (July $1^{\text {st }}$ ) participants were sent an email informing them that the information from the blogs would no longer be collected, and that the participants would retain control of the blogs, to delete or keep as they chose.

Participants were also informed through the consent form that all data that was gathered through the study would be destroyed one year from the conclusion of the study. Table 1 lists the sources of data collected from each participant.

\section{Table 1}

Sources of Data Collected from Participants

\begin{tabular}{|c|c|c|c|c|}
\hline Participant & $\frac{\text { Number of }}{\underline{\text { blog posts }}}$ & $\begin{array}{c}\begin{array}{c}\text { Number of } \\
\text { comments (total) }\end{array} \\
\text { nom }\end{array}$ & $\frac{\text { Number of replies }}{\text { to comments }}$ & Interviews \\
\hline Dorothy & 10 & 18 & 7 & $1^{\mathrm{st}}$ \\
\hline Sonia & 15 & 15 & 6 & $1^{\mathrm{st}} \& 2^{\mathrm{nd}}$ \\
\hline Laura & 2 & 0 & 0 & $1^{\mathrm{st}}$ \\
\hline Mary & 5 & 4 & 1 & 0 \\
\hline Eva & 8 & 10 & 6 & $1^{\mathrm{st}} \& 2^{\mathrm{nd}}$ \\
\hline Katrina & 1 & 3 & 3 & 0 \\
\hline Julie & 6 & 17 & 1 & $1^{\mathrm{st}} \& 2^{\mathrm{nd}}$ \\
\hline Maria & 2 & 4 & 0 & 0 \\
\hline
\end{tabular}

Interview data.

Individual interviews were conducted at two intervals over the four month period of the 
study, at the one and four month marks. The interview format was semi-structured, in order to allow opportunities to explore emerging themes and ideas during the interviews. An open-ended format to the interviews further supported the meaning construction of the participants, and allowed opportunities for them to share their own backgrounds and experiences, which supported further understanding of their individual contexts. The interview guides for the first and final interviews are attached as Appendices A and B. The interview guide for the first interview, completed one month into the study, had already been established prior to the start of the study, with only one question added during the interview process. Over the course of conducting the first interview, I added the question "What were you hoping to get out of this study?" as I hoped to get a better understanding of the learning goals of the participants. This question was then added to the interview guide and asked in all subsequent interviews. The one month interview guide began by providing a framework within which I was able to begin to understand the context and belief system of each participant. I started by asking each participant to tell me about their practice as an RECE. The participant was then asked about whether they felt that they were effective in their current role, and if they felt that they could be more effective. This question provided further insight into the participant's current practice, and also into their interest in continued professional learning and growth. The next questions explored the participant's use of their blog- their experience with regards to the process of blogging and whether they had experienced any professional change as a result of their blogging or their participation in the virtual learning community. Four of the first interviews were conducted in over the telephone using Skype, with the fifth conducted in person in a public library. Participants in the Greater Toronto and Hamilton area were given the option of conducting the interview in person, however only one chose this option. Due to distance, the other interviews had to be completed over the 
telephone. All of the interviews were recorded so that they could be reviewed in greater detail, coded, and analyzed.

The final interview guide, which was used at the conclusion of the four month study, was generated during the study based on the information generated through the first set of interviews and the content of the blog posts. The first few questions were similar to the first interview, as I asked participants to discuss: their experience blogging (including any barriers they faced), the content of their blog, whether they felt they were being reflective and/or linking theory to practice, and whether their experience in the study was having an impact on their practice as a RECE. These questions were designed to examine any potential change over the course of the study and to expand on what was discussed in the first interview. Participants were asked whether they felt that a learning community had been formed between the participants over the course of the study. Finally they were asked about their perceptions of blogging specifically: whether their opinion on blogging had changed and whether they planned to continue their blog (or to create another blog) in the future. One question that I asked during the telephone interview, but had not included in the interview guide was "Do you thinking blogging is a form of professional learning?” In retrospect, I should have included that question in the emailed interview guide, so that I would have received more than one response to the question and perhaps gained a better understanding of this from the participants themselves.

For the final round of interviews, there was a very low response. Only one participant responded and was able to complete an interview over the telephone. One other respondent completed the interview over email at her request, citing a busy schedule. In light of this, when I sent out a set of reminder emails regarding the final interviews, I attached the interview guide, giving participants the option to complete the interview over email if it was more convenient. I 
received two additional interviews in this way. Although I allowed the email interviews in the hopes that it would garner a larger response, which it did, I must also acknowledge that it limited the amount of data that I was able to gather because the email answers were less detailed than the answers from telephone interviews, and I did not have the opportunity to ask follow up or probing questions.

The telephone interviews were recorded using Skype and Amolto Call Recorder for Skype. Skype was chosen because it was a program that I was already familiar with, and had an account with, which allowed me to make calls to any phone number in Ontario. Amolto Call Recorder was chosen because it was free software, which was designed specifically to work with Skype. The in-person interview was recorded using a personal digital recording device that I already owned. All of these interviews were then transcribed using Express Scribe Transcription software, another piece of free software. The interview transcriptions were then coded and analyzed, along with the emailed interviews using NVivo. This will be further discussed in the data analysis section and findings chapter.

The reason why I chose to use semi-structured interviews alongside the data generated from the blog posts was to allow for the participants to generate ideas through their feedback and to provide the context which influenced how the data was analyzed. Through the semi-structured interviews, I sought to develop a more holistic understanding of the challenges and benefits that the RECEs experience through professional blogging, without being hindered by my own previous experiences and biases.

\section{Data Analysis}

Data was collected and reviewed at two intervals in the research process, and formally 
analyzed at the completion of the study. The data generated through the blog posts and comments, along with the data from the interviews, was analyzed with the aid of NVivo software which allowed for coding both the images and text from the blog posts and the audio transcripts. NVivo is data analysis software which allows the user to collect, organize and analyze text, audio, video and social media data (QSR International Pty Ltd, 2013). The initial open coding of the data was done using substantive codes, which were created through the words and ideas generated by the participants themselves and theoretical codes, which were generated by myself, as the researcher, using my own experiences and knowledge gained through existing theories such as Dewey, Wenger, and Schön's (Oktay, 2012). New codes were generated for each of the three types of data gathered: the blog posts, the comments, and the two interviews. I will discuss the codes generated for the content of blog posts, the comments, and interviews individually in the following sections.

\section{Analysis of blog posts.}

Each blog post was captured using NCapture, an extension of the NVivo software which allowed me to import the data directly from my internet browser into NVivo for coding. The codes used were generated throughout the process, based on the content of the blog posts. Here I will discuss how the codes were generated, with examples of the codes included later in the findings chapter.

There were two types of data gathered from the blog posts: the written content of the blogs and any included photos or videos. Although, the consent form specifically prohibited the use of photographs (see Appendix C), a few participants did still include

photographs of children's work, programming examples, and resources, such as books. As none of the photos contained identifying information about the children or programs, 
the decision was made to allow the participants to keep the photos that had posted and for myself to continue to monitor any images that participants posted to ensure they did not violate confidentiality. The reason for this was to avoid de-motivating participants by asking them to take down photos which they seemed to have used to enhance the content of their blog posts and to continue to support the open-ended nature of this study by allowing participants to use their blogs to write about any facet of their practice or the profession of ECEC. The images from the blogs were coded separately from the written content of the blogs, and were not the focus of the analysis.

There were 14 codes generated based on the written content of blog posts. Some of these codes were generated based on the overarching topic or theme of a specific post, while other codes were based on other content, such as indicators of community building or professional growth, which were woven into the content of the blog posts. The most frequently used codes were: reflection, inquiry, resource sharing, and documentation. These codes were most likely to be the overarching topic of a blog post, and were therefore considered to be themes. I will address each of these four themes in further detail in the blog content section of the findings chapter. Other codes were used with significantly less frequency and were not considered to be themes. For a complete list of codes used for blog posts, broken down by participant, please see Appendix D.

\section{Analysis of blog comments.}

The comments left by participants on blog posts were captured and coded using NVivo, in the same way as the blog posts, and the codes were generated based on the content of the comments. In total there were 71 comments made by participants in the study, from which eight codes were generated. There were two codes used for the 
comments which were the same as those for the blog posts: inquiry and reflection. This was not an intentional use of pre-generated codes, but was simply based on the content, which met the same criteria for inquiry and reflection. In addition to the codes which were generated based on content, comments were also coded by their author, which allowed me to track how involved each participant was in commenting on, and by extension reading, other participants’ blog posts.

As the comments were often brief, it was difficult to generate substantive codes based on content. As a result, the two most frequently used codes were "response" and “author response”. "Response” was used when the content of a comment was a direct response to the content of the blog post. This included responses to questions that the author posed in the original post, as well as responses to the content of the post or the author's ideas. Although all comments could be considered to be responses to either the original blog post or the comments of others, this code was only used if the response added to the dialogue of the original blog post. Comments that were simply positive or appreciative feedback, such as "Clever idea they would like that” were coded as “encouragement”. Comments in which the participant offered their own ideas, whether solicited or unsolicited from the original blog post were coded "suggestion”, while comments in which the participant posed additional questions were coded as “inquiry”. “Author response” was used to code any comment which was written by the original author of the blog post, which was almost always a response to another comment. See Appendix E for the complete set of codes used for comments, and their distribution throughout the blog posts. 


\section{Analysis of participant interviews.}

The transcripts of the two sets of interviews and copies of the emailed interviews were also coded and analyzed using NVivo. They were first coded by each interview question, and then within each question, the content was coded further. For the first interview, there were four questions related to demographics (gender, age, education level, and years in the field), and there were seven questions used to guide the semistructured interview (see Appendix A for the interview guide). Question 2 "How would you measure your effectiveness as an RECE?” and follow up “Could you be more effective?” were coded as either yes/no. Similarly, question 5 "Has blogging impacted your practice as a Registered Early Childhood Educator?” was also coded yes/no, with additional codes related to their reasoning. Both questions 3 "What has the experience of writing a blog been like?” and 6 "Have you been reading and commenting on the other blogs?” were coded based on content, and the codes were then categorized as either “positive” or "barriers”, which question 6 also including a code for "creating” community. Questions 1, 4, and 7 were coded based on the content of participant's responses and were mostly unique to each participant.

For the second interview there were six questions intended to be used to guide a semi-structured interview (see Appendix B for the interview guide). However, only one of the interviews was done over the phone, with the opportunity to explore questions beyond those from the interview guide, while the other interviews were all completed over email, strictly according to the guide, which led to much shorter responses from those participants. As with the first interview, the transcripts and written interviews were first coded by the interview questions and then by the content of the participants’ 
responses. Question 4 “Do you feel that, through reading and commenting on each other blogs, relationships or a type of community has been formed?” and 5 “Has your opinion of blogging changed since you participated in this study?” were coded as yes/no, with additional codes generated for their reasoning. Question 1 "In what ways has your experience writing the blog changed since the beginning of the study?” was coded based on the content of the responses, with a subset of codes which related specifically to barriers. Question 2 "What would you say that you typically blog about?” was also coded based on participants responses, with subsets of codes devoted to the follow up questions. Question 3 “In what ways has your experience of writing your blog and reading/commenting on the other blogs impacted your practice?” generated only two codes, as participants responses related to the opportunity to read "different perspectives" and/or receive “feedback” from other participants. Question 6 "Will you continue this blog or would you consider writing another blog in the future?” had only one code, as all responses were "positive”. There was also one other code used “professional learning”, as during the one telephone interview, I asked the question "Would you... consider blogging to be professional learning?” As with the first interview, there were quite a few codes generated based on the unique responses of participants, which were often used only once and did not align with other codes. For a full list of codes used for the interviews, please see Appendix F. Once all of the data was gathered from the blog posts, comments, and interviews, and analyzed through coding, I was able to generate preliminary theories, which will be addressed in the discussions chapter. 


\section{Findings}

In this chapter, I will discuss the key findings from the interviews, blogs, and blog comments. Through the initial email contact, and the first set of interviews I gathered demographic information. This confirmed that all participants had a diploma in early childhood education or equivalency. While I was not able to gather demographic information on all participants, I was able to gather demographic information on the most active participants, who worked in a variety of ECEC settings, were between 32 and 61 years old at the time of the study, with between 12 and 30 years experience in the field. Data was gathered from 49 blog posts, whose content revealed four predominant themes: reflection, inquiry, resource sharing, and documentation. Further data was gathered from 71 comments, left on 26 blog posts. An analysis of the comments found that most were direct responses to the content of a blog post, and there were also a couple of instances in which a conversation was generated through the comment section of a blog post. Five of the nine participants completed at least one interview. Through these interviews participants discussed how their participation in the study had influenced their practice, their experiences as part of a blogging community, and their experiences with the blogging medium, including barriers they encountered. In the following sections, I will address each of these findings in greater detail, with support from the content of the blogs, comments, and interviews.

\section{Demographic Information}

I chose to gather demographic information on the participants in order to support my understanding of the context in which they were practicing. Participants were asked their gender, age, education level and the number of years they had been in the field. 
Most of the information was gathered through the initial interview, which led to gaps in the demographic information, as not all participants completed interviews. The only demographic information that was gathered for all participants was their level of education, as this information was gathered when they submitted their blog URLs and pseudonyms. Although most of the participants who were actively engaged in the study provided their demographic information through the interviews, not having demographics for all of the participants limited my ability to generate theory related to participant`s ages or years of experience in the field.

Based on the demographic information gathered from the interviews that were conducted after the first month, these five participants (Dorothy, Sonia, Laura, Eva, and Julie) all identified as female and were between 32 and 61 years old. I have further assumed that all participants in the study were female, based on their given names. Additionally, these five participants had all worked in the field for between 12 and 30 years. Two participants had unique experiences in the field. Dorothy stated that she had worked in the field on and off for 25 years, most recently in Canada, but also had a degree in education and experience working in her country of origin. Another participant, Julie stated that she had worked in the field for 30 years, but made a point of stating that she had only received her ECE diploma two years prior.

As per the requirements for the study, all participants were self-identified registered early childhood educators, which would require that they had completed a diploma in early childhood education or equivalency. Most participants stated that this was their highest level of education, although a couple noted that they had additional education unrelated to the field of ECE. Dorothy did not have an ECE diploma, but rather 
had received equivalency through the AECEO bridging program. Maria identified having both an ECE diploma and a degree in early childhood, and Laura stated that her highest level of education was a Masters of Arts in Educational Leadership and Management. See Table 2 for complete demographic information.

\section{Table 2}

Demographic Information by Participant

\begin{tabular}{|c|c|c|c|c|}
\hline Participant & Gender & Age & Education Level & $\frac{\text { Years in }}{\text { Field }}$ \\
\hline Dorothy & Female & 41 & $\begin{array}{l}\text { Bachelor's degree (international) \& } \\
\text { ECE equivalency through AECEO }\end{array}$ & 25 years \\
\hline Sonia & Female & 32 & ECE diploma & 12 years \\
\hline Laura & Female & 37 & $\begin{array}{l}\text { Masters of Arts in Educational } \\
\text { Leadership and Management }\end{array}$ & 14 years \\
\hline Brittany & $\begin{array}{l}\text { Assume } \\
\text { Female }\end{array}$ & No Data & ECE Diploma & No Data \\
\hline Mary & $\begin{array}{l}\text { Assume } \\
\text { Female }\end{array}$ & No Data & ECE Diploma & No Data \\
\hline Eva & Female & 42 & ECE diploma & 18 years \\
\hline Katrina & $\begin{array}{l}\text { Assume } \\
\text { Female }\end{array}$ & No Data & ECE diploma & 12 years \\
\hline Julie & Female & 61 & ECE diploma & 30 years \\
\hline Maria & $\begin{array}{l}\text { Assume } \\
\text { Female }\end{array}$ & No Data & $\begin{array}{l}\text { ECE diploma and degree in Early } \\
\text { Childhood }\end{array}$ & No Data \\
\hline
\end{tabular}




\section{Context}

To further extend my understanding of the context in which participants were practicing, during the first interview participants were asked to describe their practice. Adding to that data, several of the participants used their first blog post to introduce themselves, providing additional contextual information. Participants worked in a number of different capacities in the field, including Full Day Kindergarten (FDK) programs, child care programs, post-secondary programs, and in program and quality support programs.

Three participants, Dorothy, Sonia and Maria, worked as Designated Early Childhood Educators (DECE) in FDK programs. In her first blog entry, Maria wrote that she was in her first year of working with the school board and in the FDK program, stating that she works "with a range of diverse students and families and the experience of full day kindergarten has been lets just say a world-wind adventure”. Through their interviews both Dorothy and Sonia discussed their experiences working in partnership with the kindergarten teacher in FDK and seemed to have different experiences in terms of their roles in the classroom. Sonia stated that she had worked with the same teacher for five years, stating that it had taken some time in the beginning to work out their roles but that for the last couple of years the relationship has improved:

We trust each other, we bounce ideas off each other. She knows that I know, you know, what the curriculum is, and all the expectations, and we both share the workload. I might be doing a circle, she might be doing a circle. I might be planning lessons, she might be planning lessons. We both sit to do report cards 
together and it seems to work well that way, and she said that she really likes my input and welcomes it now. So, we have a great relationship right now.

Dorothy also described her relationship with her teaching partner in a positive way, but her description of their roles was different than what Sonia described:

My teacher she prefers to do math and she teaches, right? ECEs don't teach at school but we actually, we do art... If it's math, she teaches, so every single day she has a, let's say, lesson that she does, but if it's me, I just do games with them based on the lesson she's doing during the week...I don’t read with them. I do circle time with the singing, with the games and usually I keep them busy when they getting ready to go home.

Another three participants, Laura, Eva, and Julie, worked in a training capacity. Laura was a partial load faculty in a post-secondary early childhood education program. Eva worked as a consultant as part of a quality initiative in her region. She described her role this way:

Training other professionals or other people working in the sector, with some of the observation tools to assess the programs... Supporting the staff and further enhancing their practices, whether it be through coaching conversations or helping them find resource so they can either further their training or education, I guess. Could be supporting them in finding resources that are available through the organization where I work. 
Julie worked in a "small daycare in a rural area" and while she did spend some time daily in the classroom environment working directly with children, that's not her main role. She described her practice this way:

Right now I'm working mostly with behaviour management because that's one of things that I do. I do Triple P as well... so I work on behaviour management. Right now we're doing a pilot project for the [city] health unit, in putting Triple $\mathrm{P}$ into the ECE class, like our ECE classrooms. So I'm doing that and then I work on talking to staff, and helping them as much as I can, or learning with them, about documentation and reflective teaching and that sort of thing. So, I also do a lot of media for the place.

I was able to gather little to no contextual information on the other three participants. On her first blog post, Katrina noted that she had been working in the field for 12 years, and was currently working in an administrative positive, but provided no further details. Similarly, while Mary also completed several blog posts, no contextual information was provided on her blog, and she withdrew from the study prior to completing any interviews. Finally, although Brittany consented to be in the study, and created a blog, she never made a single post or comment, nor did she respond to interview requests, so I have no further information on the context in which she practiced.

\section{Blog Content}

All of the participants, except one (Brittany) wrote at least one blog post. Over the four months of the study participants were asked to complete a minimum of one blog post per week, which would have been a minimum of 17 posts. Only one participant, Sonia, 
came close to meeting the proposed number of blog posts, completing 15, although it should also be noted that Mary, who withdrew from the study at the 6 week mark, had written 5 blog posts at that time, adhering to the one blog post per week guideline. The total number of blog posts that each participant completed ranged from zero to fifteen, with the mean being 10.4 posts, and the median being 5 posts. In total, I gathered data from 49 blog posts. Table 1, in the data collection section of the findings chapter, addresses the number of blog posts, comments, author replies to comments, and interviews that each participant completed.

\section{Reflection.}

The most frequently used code was "reflection”, which was used in about half of all blog posts. Reflection was used to code any examples of participants reflecting on, and/or questioning their own beliefs and practices, or the practices of others. It also included instances of participants attempting or re-attempting new programming ideas, and their observations about their students and programs. To provide an example of blog content that was coded as "reflection", I will use content from two connected blog posts from Dorothy, a participant who works in a FDK program. In the first post, she talked about an idea brought back from a colleague regarding "loose parts” and glue less crafts. Dorothy discussed setting up the craft table with the loose parts and a paper base. She first noted that a few children chose not to work at the craft table once they realized there was no glue. Dorothy stated what she observed the children do and how she supported their learning, noting "But I can see that they are losing interest to work in the craft centre”. She modified the materials at the centre, increasing the amount of loose parts but said "I got less students at the table [original emphasis]". Dorothy went on to say that she 
read a book on loose parts, which she enjoyed, but noted that she still did not have children interested in creating without glue. She ended the first post asking "Do our students don’t have enough imagination? Do you think I made a mistake to stop using glue? Do you have any ideas how to engage the children to work with the loose parts?”. In a follow up post about a week later, Dorothy stated that she once again worked with loose parts in the craft centre, writing "But at this time I left long white piece of paper on the table along with the loose parts we have. I stayed with the children because I didn't want to miss anything they were talking about”. What followed this was a series of photographs of the work that the children had created with their loose parts and documentation of the language the children had used during this exploration. These two posts were coded as reflection, and seemed to be examples of Schön's concept of reflection-on-action, as Dorothy brought forth new ideas, and modified her ideas multiple times based on her observations. There also seem to be indications of Dorothy's use of reflection-in-action as she describes in her first post how she modified the amount of loose parts available, as she noticed the children losing interest in the centre.

\section{Inquiry.}

Both entire blog posts and portions of blog posts were coded with the term "inquiry". A post was coded as "inquiry" if the purpose of the post seemed to be seeking feedback from the broader community regarding a specific issue. An example of this would be from Eva, who regularly posed inquiries, often in conjunction with case study type examples. Her post “Meal times - Is it a stressor?” was entirely inquiry based, containing only questions. The brief post was as follows: 
During your lunch time routine, do you have the opportunity to sit down with the children in your program and have conversations with them? Are you able to support them in building their self-help skills, such as pouring or serving themselves?

Or are you serving the meals, cafeteria-style where the children line up to get their food? Or are you constantly getting up and sitting down to serve children at different tables who want "more” of something?

Are mealtimes an exhaustive routine?

An example of an inquiry embedded in a larger post would be from Julie. In her post "Puddles and Jumpers" she discussed some of the ways that the children in her program engaged outdoors, particularly in puddles, and ended her blog post with "How do you extend the time you spend outdoors, all suggestions would be appreciated?” I felt that it was important to make note of the inquiries made in the content of blog posts, whether or not they were the focus of the post, because these inquiries reflect not only ideas of professional learning, but may also serve to build community between the participants.

\section{Documentation.}

Participants would often write their blogs posts based around a particular planned experience or exploration that occurred in their classroom. Posts that discussed these types of experiences may have included observations about the children, and details or instructions related to the materials used. These 18 posts were coded "documentation", as their focus seemed to be documenting a certain event in the educators practice. One example of this would be from Sonia’s blog, in her post “Mix it Up!” She begins the post 
by introducing a new book she had recently purchased and read to her kindergarten class. She goes on to document the planned activity she facilitated, step by step:

Each child picked two primary colours to mix. They then made a prediction of what new colour they would make. After that, they dabbed a bit of one colour in one box on the worksheet and the other colour in the other box on the worksheet.

Sonia also included photos of both the children's work and materials to support her description. This type of post was typical for Sonia, as when asked in her first interview what she typically blogged about, she responded, "the main focus is sharing some ideas that I've done in my classroom with other educators; with specific pictures, with step by step". She went on to say that she wanted to share ideas which other educators could use in their own practice. Dorothy and Julie had similar ideas, stating that they used their blogs to discuss activities and their work in the classroom.

While most of the blog posts which were coded as “documentation” were about children's learning, there was one post which dealt with educator learning, which I also coded as documentation. Eva, in "Exploring Creativity \& Intelligence", wrote about her experience participating in a "communities of practice group". In this post she gave a recap of the discussion that she and her colleagues had had in her group, including some of the questions that were posed to the group, as well as their responses:

We then discussed, what being "creative” really means to us. We all concluded when we think of being creative, we automatically think of artists (such as painters, sculptors, photographers, musicians etc) as well as designers (such as graphic designers, fashion designers and interior designers). But we also agreed 
that anyone that "thinks outside the box" is creative as well (think of all those people who wanted to create or discover something such as Steve Jobs or Albert Einstein).

Eva also added some of her own thoughts, and embedded the video into the blog post, alongside a few thought-provoking questions. Although there were certainly elements of this post which were also coded as "inquiry", I felt that this still fit the theme of "documentation", as it documented the process of educator learning in much the same way that other posts had documented children's learning.

\section{Resource sharing.}

Participants also frequently used their blogs as a means to share resources. Nineteen blog posts, just less than half of the total amount, included one or more shared resources. In addition to sharing programming ideas, participants shared videos, books, articles, programming materials, and websites. While these resources were often the focus of the blog post, being presented either with or without comment from the writer, resources were also included in blog posts where they were not the main focus. There were also a few posts where the authors used the shared resource as a jumping off point

for inquiry and reflection. For example, in an untitled blog post, Dorothy provided a link to the Ministry of Education's website, specifically a page on Observation, Documentation and Interpretation in Early Learning. She included a few documentation related snippets from the website, adding:

I am looking for ideas and advices about documentation. If I use a language sample should I make a conclusion what that means for me? Do you have any 
ideas about learning stories? Could you please, share your experiences how to do it and how to use it for documentation?

Another simple idea that was shared was from Eva, who wrote in a blog post titled "Nature in the Classroom":

I saw a great idea in a Toddler Room recently! The teacher wrapped plastic mesh around a potted plant (it was adhered at the top of the pot with twine), so the Toddler children would not be able to dig in the dirt of the plant... I thought this was a great modification, since children can still assist in watering the plant, see the soil and appreciate natural material, without the teachers getting frustrated with the children's exploration of the dirt.

In Eva’s final interview, she discussed the value of these shared resources, saying “I really enjoyed when they either had a link or a book recommendation. I thought that was kind of interesting... writing it down and having it somewhere so if I need to refer to it, I can”. At times, these resources also sparked conversation in the comments, which will be discussed in the next section of the findings.

\section{Blog Comments}

Another question which I asked through this study was "In what ways do RECEs engage with each other through their blogs and comments?” I will begin by addressing the comments specifically, and then move on to discuss the other ways in which the participants engaged with each other during the study.

One of the defining features of a blog is that it allows readers to make comments on a specific blog post. This can provide a medium for readers to ask questions, give 
feedback, or share their own experiences. Similarly, writers can respond to their readers' comments providing an opportunity for ongoing exchange, and the beginnings of community formation. For the purposes of this study, in addition to writing blog posts, participants were also given the URLs of the other blogs in the study and asked to read and comment on one other blog post each week. Comments were left on 26 blog posts, and the number of comments on these posts ranged from one to eight.

There were a few instances in which a blog post sparked back and forth discussion between participants. For example, in an untitled blog post, Dorothy discussed a book she'd borrowed from the library Kids Play Igniting Children's Creativity by Michele Cassou. Dorothy included several quotes from the book in her blog post, in which the author notes three questions which educators should avoid asking children about their art, and why they should be avoided. In the comments, participants responded with their own agreement and disagreement over the ideas that Dorothy shared from the book. Dorothy, in turn, responded to the comments, including the following:

After reading all replies from my followers I understood one thing. Every teacher creates his/her environment that is unique and built on children's interests and abilities. I am looking forward to hear from you about wonders and exploring literacy through the wonders.

During her first interview, Dorothy referenced this same blog post, while discussing what she typically blogged about. She said that when she found something interesting, she wanted to share it, so she blogged about it. She went on to say that she thought this post had been a particularly good idea, as it had received numerous comments. 
In addition to commenting, there were other ways through which participants interacted. In response to one of Sonia's blog posts about rainbows and light, Dorothy planned an experience in her own classroom, which she wrote about on her blog. Another participant, Laura, extended an invitation of sorts through a resource that she shared. In a blog post where she discussed using technology to share and communicate, Laura shared “tonight I am super excited to be participating in a Tweet Chat hosted by Jim Grieve...Tonight the focus is on Family Engagement and I am keen to participate in this dynamic opportunity". She went on to provide details of the event and how to participate, ending with "[h]ope to see you there”. While there are numerous examples of interaction between participants, to fully address the concept of community, it is important to include the perceptions of the participants, which were gathered through interviews, as addressed in the next section of the findings.

\section{Interviews}

Through this study, I used interviews to better understand the experiences of the participants. I asked questions related to their practice, and the content of their blogs, which were included earlier in the findings. Through their responses I found that their participation in the study had an impact on their practice, that a virtual learning community was in an early stage of development, and that the participants had an overall positive experience creating and maintaining a blog. Here I will share the perceptions of the five participants who completed interviews, as they relate to these three topics.

\section{Impact on practice.}

There was some indication that writing a blog and engaging in a virtual learning community had an impact on the everyday practices of the RECEs in this study. 
Participants were asked during both interviews to discuss how their participation in the study (writing blog posts, and reading and commenting on other participants’ blog posts) had impacted their every day practice. During the first interviews, most of the five participants felt that it had had some degree of impact, from motivating them to think about what they want to write about, and by extension what programming they want to do in their classrooms, to idea sharing with other participants. Other participants acknowledged that they could see the potential for change in either their own practice or another educator's practice, even though they were not experiencing it themselves. The answers were similar at the second set of interview for most participants; however Julie, who had initially said that she saw the potential for changes in her practices, said that she did not think she had actually experienced any change in her practice, stating "often I felt the ideas [were] more teacher directed then I like to do”.

\section{Community building.}

Although the participants' had mixed responses when directly asked whether they felt a community had been formed through the study, there was evidence of community building through both the participants' feedback in the interviews, and their engagement with each other through comments. Based on the stages of community of practice development as outlined by Wenger (1998), the community built based on this study would be in the stage of "coalescing”, as the participants were only beginning to come together and to see the potential for the community. As Julie put it in her interview, "I think that once we all get a little more comfortable with just the whole experience that maybe we'll get more invested in what we say to each other”. 
At both interviews participants were asked about their experiences connecting with other participants through comments. In the first interview, they were asked whether they had been reading and commenting on the other blogs, and all of the participants said they had been reading the blogs. Only one participant, Laura, said that she had not yet commented on any of the blogs. She did, however, express a desire to, stating that she sometimes thought- "well I'll come back to that later because I want to say something really meaningful and then I get distracted”.

More significant, however, was what they said about their experiences with seeking feedback or receiving comments. Most participants said that they enjoyed receiving comments, and participating in “conversations” through the comments. A couple participants also mentioned that they sometimes struggle to come up with comments, as they do not always know what to say. One participant, Sonia, even made a point of saying that her next goal was to elaborate on her comments and ask questions, noting that most of her comments up to that point were usually just appreciation or praise. Another participant, Dorothy, seemed to lose motivation when she put up a blog post and did not receive any comments in return, saying- "If you see like nobody replies, there is no comments. Probably that's why [I would stop posting]”.

At the final interview, participants were asked if they felt a community had been formed through reading and commenting on each other's blog posts. The results were split down the middle, with two participants stating that they felt a community had been formed, and the other two feeling that a community had not been formed. Those who agreed that a community had been formed, felt that (at least some of) the other bloggers 
had been responsive and supportive, and willing to engage, which those on the other side felt that there had not been enough exchanges for a community to have been formed.

\section{Blogging experience.}

When asked in both the first and second interview about their experience blogging, participants were mostly positive. They seemed to enjoy getting the blog set up and sharing some of their experiences. Only one participant seemed to struggle with Wordpress, the blogging platform that was used, while the other participants seemed to have found the process of setting up their blog to be easy. However, at both the first and second interview, participants mentioned a number of barriers that they had faced during the study. The most frequently cited barrier at both intervals was finding the time to write a blog post or to read and comment on the other blogs in the study. Other barriers included: lack of confidence in their writing skills, finding ideas to write about, and staying motivated, especially as overall participation began to drop towards the end of the study. In the final interview, when asked if their opinion of blogging has changed, several participants noted that it was more difficult and time consuming than they had initially thought. However, their overall response to blogging was positive, as all four participants who completed the final interview stating that they would like to continue writing their blog or would consider starting a new blog in the future, each of them acknowledging that they would need to continue to work around the barriers they had faced over the course of the study.

\section{Association between Blog Content and RECE Context}

The participants in this study worked in different capacities in FDK programs, child cares, post-secondary institutions, and quality support programs. While all of the 
blog posts were related to the profession of ECEC, the type of content that came out through each participant's blog seemed to be unique to their own experiences, current practices and intentions for their blog. Participants who were currently involved in front line practice, such as Dorothy, Sonia, and Maria, seemed to focus on idea and resource sharing, with most of their posts coded as documentation, inquiry or resource sharing. Eva, who worked as a quality consultant, expressed a different intent with her blogging. In her interviews she stated that part of her intention through her blog posts was to elicit a response from her readers. She would frequently pose questions, sometimes accompanying scenarios which were based on an amalgamation of conversations she'd had or observations she'd made in her practice. In her first interview, she described the intention behind her blog posts this way- "I guess trying to find out what best practices are and how other people are practicing and how they overcome... the trials and tribulations of trying to have these best practices happen in a best practice manner”. Although she withdrew from the study after completing only five blog posts, Mary also had a unique intent for her blog. She stated in her first post- "This is a platform created to talk about Early Childhood Educators’s mental health”, and subsequent blog posts seemed to adhere to this theme. This diversity in content supports an understanding of professional learning as being context-depending, which will be further addressed in the discussion chapter. 


\section{Discussion}

\section{Summary of the Results}

The availability of the internet and the development of new technological mediums create new opportunities for professional learning. Educators are increasingly turning to the internet and social media for information and inspiration for their everyday practices. Organizations, such as the AECEO, are offering online webinars, educators in child care and full day kindergarten programs are creating blogs, while others are establishing a social media presence through Facebook or Twitter. In my own practice as a RECE, I maintain professional social media accounts, including a blog. It was for these reasons that I felt it was important to explore how RECEs were using blogging to document or reflect on their own practices, and as a means to connect with other educators.

The main research question I asked through this study was whether blogging in a virtual learning community was an effective form of professional learning for RECEs. While, I am not able to make a firm conclusion one way or another, I have been able to generate a number of preliminary theories based on the content of the blog posts and comments that participants wrote, as well as their perspectives of the experience. Over the course of this four month long study, I have learned alongside the participants, as a researcher, and also as an early childhood educator. In the following sections I will discuss the theories that were generated, the limitations of this study and how it fits with previous research, and finally how the findings of this study are significant for the ECE profession in Ontario. 


\section{Discussion of the Results}

My intention with this study was to develop an understanding of the way in which RECEs use blogging as a medium for professional learning. As the College is seeking to mandate continuous professional learning activities for all RECEs, which will include engagement in virtual learning communities and blogging, I felt it was important to examine how these mediums can be used for this purpose. Through this, I asked a number of questions, and have been able to generate four preliminary theories which I will discuss here. First, I will address the relationship between the professional contexts of RECEs and their use of the blogging medium. Second, I will discuss the use of reflection through blog writing, and how this relates to professional learning. Third, I will discuss the formation of a virtual learning community through blogging. Finally, I will discuss whether blogging is an effective form of continuous professional learning for RECEs.

\section{The association between blogging and RECE contexts.}

One of the preliminary theories generated through this study was that the type of position that an RECE holds will influence the content of their blogs, and their interactions with other bloggers. Ontario RECEs work in a variety of settings, including licensed child care, full day kindergarten, and family and community resource programs. They may be front line staff, supervisors, administrators, consultants or educators. In line with this, the participants in this study worked as administrators and support staff in child cares, designated ECEs in full day kindergarten programs, a faculty in a post-secondary program, and a quality consultant for a community support agency. Each participant had their own intentions and goals through their blog, which related to their current practices. 
This was reflected through the content of their blog posts, which showed that front line RECEs were more likely to document and either seek or share ideas and resources, while those who worked in a training or support capacity were more likely to try to elicit a response from readers, through inquiries or case studies. This was further confirmed through the initial interviews, during which front line RECEs spoke about wanting to gain or share programming ideas, while RECEs in training or supportive roles talked about wanting to get a better idea of the experiences of RECEs or to start discussions related to quality practices.

When I designed this study, I intentionally chose to include RECEs working in any capacity in the field, as I wanted to get the full picture of how RECEs in different contexts use the blogging medium. I believed then, and continue to believe, that RECEs can learn not only from others in similar positions in the field, but also from those with different experiences. However, in reflecting on my findings, I am forced to question whether the variety of contexts limited the development of a virtual learning community. Two of the most active participants (Dorothy and Sonia) both worked in full day kindergarten classrooms, and seemed to connect more with each other than with the other participants in the study. There was at least one instance in which Dorothy was inspired by something that Sonia had done with the children in her class, and planned a similar experience for her own class. While overall participants seemed to respond positively to the differences, I am unsure whether being "interested" in different practices is sufficient to promote professional learning. I also have to wonder whether a more active community of practice would have been formed if all of the participants had been working in similar contexts; limiting the study to only RECEs working in full day 
kindergarten classrooms, for example. Wenger (1998) identified three dimensions of a community of practice: joint enterprise, mutual engagement, and shared repertoire. Perhaps RECEs who engage in similar practices would experience a stronger sense of connectedness which would support the development and maintenance of a blog-based virtual learning community.

Furthermore, my findings are in line with previous studies about professional learning which have posited that context is an important factor in determining the professional learning needs of individual educators (Edwards \& Nuttall, 2009; Lehrer, 2013; OECD, 2012; Opfer \& Pedder, 2011; Shore, 2012). Opfer and Pedder (2011) posited that educator learning include three overlapping systems: the individual educator, the school/program, and professional practices. It is for this reason that I gathered information on the context of each educator, with information about each of these three systems. While most of the literature has focused on context being significant in the efficacy of different types of professional learning, based on the data that I have gathered, I believe that the context of an individual can also influence the way in which they use a particular form of professional learning, in this case blogging and engaging in a virtual learning community. As blogging is an open ended medium, it allows for users to create content and engage with their readers in a way which is valuable and practical for their own purposes. The challenge, however, with the open ended nature of blogging is that, although it can be used in numerous ways which promote professional learning, it can also be used to perpetuate incorrect information or practices, as Byington (2011) previously noted. Therefore it stands to reason that, as with other forms of professional learning, it would be important to assess whether the blogging would be an effective form 
of professional learning for an RECE working in a particular context. The challenge with assessing the effectiveness of professional learning, however, is that it is an internal process and may not be easily observed or evaluated. I found through this study, it was difficult to determine whether professional learning had occurred. A longer term study may yield more evidence of changes to practice, which would be one way by which effectiveness could be assessed.

\section{Reflection through blogging.}

Another preliminary theory that was generated is that RECEs engage in reflection through writing blog posts. One of the most prevalent themes which emerged through the content of the blog posts, which was also present in some of the blog comments, was that of reflection. Participants used their blogs to reflect on their practices, as well as their previously held beliefs. The length of the study, and open ended nature of blogging, limited my ability to assess whether participants were making significant changes to their practice based on their reflections. However, there were indications that participants were using their blogs to document some of their reflection-in-action, as coined by Schön (1983), as well as to engage in reflection-on-action related to their practices. For example, as previously discussed in the findings chapter, Dorothy documented her own reflections regarding removing glue from the craft area in her classroom in order to encourage loose parts exploration. Furthermore, with the introduction of comments from other participants, Dorothy was given additional feedback upon which to reflect, which would be in line with Rodger's (2002) assertion that reflection occurs in the context of community. 
Originally, I had set out to specifically look at blogging as a form of reflective practice, and had adapted a framework with levels of educator reflection, based on Harland and Wondra (2011). However, I found that when I attempted to fit an entire blog post into a single category, I was sometimes forced to undervalue small points of reflection or inquiry within a post which may have seemed to be more nonreflective or descriptive overall. I also found that using a pre-established framework to code entire blog posts did not fit with my social constructivist framework and my research paradigm of grounded theory. Instead, through the use of open coding, I was able to pick out elements of reflection in the content of blog posts, comments, and even during the interviews, all of which allowed me to conceptualize reflection as an element of blogging, and not necessarily the basis for all blogging. The more I considered this, the more it affected the way that I reviewed previous literature. I previously noted that when it comes to professional learning, much of the literature that is available, especially in recent years, seems to be predicated on the idea that reflection is essential to professional learning. Applying this idea to blogging, I began to wonder: does each blog post need to be reflective? Is there still something of value to be gained from writing (and reading) a blog post that is not reflective, or contains only small points of reflection? While I am not able to answer any of these questions definitively, I believe that both reflective and nonreflective blog posts can have value. For example, there were a number of blog posts which were considered "resource sharing” posts, which often contained no elements of reflection, yet participants expressed their interest in following up on these resources, showing their value. Therefore, I think it is important to note that, while RECEs do engage in reflection through blogging, they may also include resources or other types of 
content in their blogs that, while not reflective, may still contribute to professional learning.

\section{Creating community through blogs.}

Blogging is a social medium and because of this, one is not able to examine the experiences of RECEs creating and maintaining blogs without also addressing the social component. In this study, to encourage the development of community, participants were asked to comment on other participant's blog posts, in addition to writing their own. As previously discussed in the findings chapter, participants did comment on each other's blogs, and often authors responded to those comments, which lead to back and forth discussions. Based on this, I posit that blogging is a medium which promotes the development of virtual learning communities.

Although the participants themselves were divided as to whether or not they felt a community had been formed through this experience, I believe that there was enough evidence of interactions and influence to argue that a community was formed, albeit in an early stage of development. It should also be noted that because this study had a very small number of active participants, they were arguably at a disadvantage in the formation of a community, as Byington (2011) found that active participation was an important part of the formation of virtual learning communities. I think that because such a small group of individuals showed signs of a coalescing community of practice, there is significant potential for virtual learning communities to develop through larger communities of educators who blog or engage with one another through social media. 


\section{Blogging as a form of continuous professional learning.}

As this study began with the premise of examining blogging as a medium for continuous professional learning, I sought to draw a conclusion based on my findings. While I was not able to definitively establish that blogging is an effective form of continuous professional learning through participant feedback or significant indicators of change in practice presented in blog posts, I have nonetheless come to a conclusion. I continue to believe that blogging can be an effective form of continuous professional learning. This sentiment was echoed by several participants during their interviews, including Eva who said:

I've observed certain things ... I just want to [put] it out there in the atmosphere that ...if someone else was partaking in this blogging project that they might read this and read other people's perspectives and they might either change their practices or change their thinking or do some more thinking.

As previously stated, through this study I have generated theories that RECEs use blogging to engage, and to build virtual learning communities. I have also theorized that the ways in which RECEs use blogs is dependent upon the context of their practice, and perhaps even their understanding of technology. Bearing this in mind, I think that it is important to address the barriers that were identified by participants in this study, as they could be seen as the variables through which blogging is or is not an effective form of continuous professional learning. At both interviews, participants were prompted about any challenges or barriers they faced during their experience blogging. The barriers that they identified included: finding the time to write a blog post and to read others posts, learning to use the blogging platform, lacking confidence in their writing abilities or the 
value in what they have to share, and determining what to write about on their blog. Most of these barriers were identified by multiple participants, and are in line with what previous studies have found (Byington, 2011; Yang, 2009).

Examining these identified barriers together, and combining that with the low participation level in the study, I would also argue that motivation plays a significant role in the use of blogging as a form of professional learning. I think that if an individual is interested in blogging and motivated towards starting a professional blog, then many of the listed barriers will either be mitigated or eliminated entirely. If reading or writing blog posts becomes a priority, then the RECE would make time for it. As Byington (2011) posited, active participation is important in the formation of a learning community, which means that it is not enough for RECEs to be motivated to write their blog, but they also need to be motivated to read other blogs, to read and reply to comments, and to be motivated to engage with the blogging community. I would further suggest that, if educators have a desire to share their ideas and experiences through a blog, they will likely have an easier time coming up with ideas for posts, and finding the confidence to put those ideas out onto the internet. Speaking from my own experience, while my use of blogging has not always been consistent, when I find my motivation, when I am inspired by an idea, I make the blog a priority, finding the time and confidence to share my thoughts. The community that I engage with online is often one of my motivators. For example, if I read something I want to respond to from another blog, or if I get a lot of responses to a particular blog post, I am motivated to write. This is also consistent with the literature discussed earlier , which indicated that motivation is a key factor in an individual use of blogging for reflection or professional learning (Killeavy \& 
Moloney, 2010; Lin \& Yuan, 2006; Lindgren, 2012; Luehmann, 2008; Shoffner, 2009; Yang, 2009).

There is also a link to be made between this idea of motivation being a key factor in the use of blogging as a form of professional learning and the idea that professional learning is context dependent. As Shore (2012) argued, professional learning cannot be "one size fits all”, as not all educators have the same readiness or willingness to make changes in their practice. I think this is significant for blogging in particular, because although it is a social medium, a blog could be kept without the author reading the comments or engaging with their audience in any way. Therefore I think it is not only important for an individual to be motivated to blog, but for effective professional learning to occur they must also be motivated to engage with their audience, to reflect on what they have written, and to make changes in their beliefs and practices. In conclusion, while I believe that blogging can be an effective form of continuous professional learning for RECEs, I do not think that it can be effective for all RECEs.

\section{Implications for Future Research and Practice}

While I was initially quite disappointed with the low levels of participation in this study, once I began to conduct interviews, and analyze the data, I found that I was able to make connections and generate preliminary theories. For this reason, I would posit that one of the most important findings of this study is that there is enough evidence to support the use of blogging as a form of professional learning, and that further inquiry is warranted. While this was a small study with a limited sample size, there was enough data to generate preliminary theories, and to make connections to previous literature. The data also raised a number of questions, including how context relates to blogging and 
virtual learning communities, and whether reflection is a necessary part of blogging and professional learning, both of which I believe warrant further inquiry.

The findings of this study also have implications for RECEs currently in practice in Ontario. This study was inspired, in part, by the Continuous Professional Learning program established by the College, which will potentially become mandated for all RECEs in the near future. However, as previously discussed, the types of professional learning activities proposed by the College were derived from the feedback of RECEs in Ontario, and have not necessarily been grounded in research as to their efficacy. My intention through this study was to explore two of these proposed professional learning activities (blogging and online communities of practice) with the hope of being able to determine their efficacy. While I was not able to definitively establish that either of these activities would support continuous professional learning, I was able to find data to support the potential for learning to occur through these activities. It is my opinion that these findings may be of interest to the College, as well as to RECEs who are considering creating a professional blog to support their own professional learning and practice.

For instance, the College (2014a) has included engagement in online communities of practice as one of the proposed continuous professional learning activities. However, they do not address how an online learning community supports professional learning. Based on this study, I would present the following as opportunities for professional growth through a blog based learning community: (1) feedback, (2) validation, (3) information, and (4) inspiration. 
(1) Opportunities for feedback from professional peers when the blog is used to document planned or spontaneous learning experiences, as well as opportunities for continued dialogue through the comments feature. This would allow RECEs to receive constructive feedback, as well as providing opportunities to reflect on their own practices.

(2) Opportunities to share challenges and experiences, and to connect with other educators who have had similar experiences. This would not only provide a sense of validation, supporting RECEs to no longer feel alone in their challenges, but also provide a forum through which strategies can be shared.

(3) Through blog posts, as previously discussed in the findings chapter, RECEs can share information and resources. Through reading the blogs of other RECEs, educators could potentially keep up to date with current research, theory, and quality practices.

(4) Through reading and commenting on blog posts written by other educators, RECEs could have their own practices or beliefs challenged, causing them to reflect on their own practices, and perhaps even make changes. They could be similarly inspired to try new ways of programming, setting up their environments, or even interacting with children and families.

One of the challenges with face to face communities of practice is that educators can be limited by being surrounded by others who have similar beliefs, and practices, which may not support further reflection or critical thinking, as they consistently receive the same types of information, feedback, and support. Virtual learning communities allow opportunities for educators to connect within their local area, but also outside of their 
geographic location, potentially connecting with educators around the world. I think that this potential to engage with a diverse set of educators would support RECEs to reflect on their own practices, and to seek out new ideas, in line with what the College has proposed for professional learning.

\section{Limitations of this Study}

There were a number of limitations within this study, the most significant limitation being the size and scope of this study. As this study was completed as part of a Masters program, it was done with limited resources over a short period of time. For this reason, the sample size was limited, garnering only nine participants, one of whom withdrew about six weeks into the study, and with only half of the participants actively participating in blogging, commenting and completing interviews. As such, most of the findings and theories were generated based on the experiences on four RECEs, working in a variety of ECEC settings across Ontario. Additionally, it was difficult to assess whether changes in thinking or practice had occurred given both the open ended nature of blogging and the short time span during which participants wrote blogs. It is possible that change in thinking or practice did occur, however, which was not evident through the participants' blogs or comments.

There was one restriction that was placed on the study for the protection of confidentiality which turned out to be a much more significant limitation than I had anticipated. In consultation with Ryerson's Research Ethics Board, the decision was made to restrict participants from using photos on their blogs. While there were a couple of blogs which did include photos (which did not include identifying information), several participants who did not violate the restriction expressed frustration over this 
matter. As Julie wrote in her final interview "The no pictures clause hampered me much more then I thought that it would...Many times I went to write something and realized with out pictures it was almost impossible to explain”. Additionally, because there were a couple of participants who continued to post photos (which did not include children or identifying information) despite the restriction, I received feedback from the participants about the value in seeing the photos, especially from Eva who identified herself as a visual learner. The ability to add photos and other media is one of the advantages to the blogging medium, and this restriction may have limited participants from getting the full experience of blogging. Reflecting on this, if I had the opportunity to complete a study like this again, I would try to find a compromise with regards to photos, which would protect participants from issues related to confidentiality, but still allow them to share certain photos as part of their blogging practice.

Another unanticipated limitation of the study was that, although participants' blogs were public, the participants were under a confidentiality agreement which did not allow them to share their blogs with those outside of the study. In addition to this, due to the short amount of time of the study and because the participants were mostly unfamiliar with the blogging medium, they were not able to optimize their blogs to be found by search engines, which meant that there were limited opportunities for those outside of the study to provide feedback or to become a part of the virtual learning community, as I had initially anticipated would happen. Again, considering how I would change the study, I would not want to further complicate the participants' blogging experiences through the addition of more technology, such as search engine optimization (SEO) tools. However, one way in which a virtual learning community could potentially extend beyond the 
participants in the study would be to ask participants not only to comment on the other blogs in the study, but also to seek out additional blogs written by other educators to read and comment on.

While this study was limited in its size and scope, and through restrictions implemented to protect the confidentiality of the participants and the programs in which they practice, these limitations also provided valuable insights for future research studies with similar methodologies. Furthermore, without the photo restriction, I may not have appreciated the value of photos as part of a blog's content, both to support the blog writer to document and explain, and for the blog reader to understand and become inspired.

\section{Conclusion}

Based on the data gathered through this four month long blogging study, I have determined that blogging in a virtual learning community can promote professional learning in Ontario RECEs under certain conditions. Using a social constructivist framework and grounded theory, I generated preliminary theories based on my analysis of blog and comment content, as well as the feedback I received from participants through two sets of interviews. I determined that RECEs are able to engage in reflection through blogging, that the blogging medium can be used to establish a virtual learning community, and that the context in which an RECE practices influences the way that they engage with the blogging medium and a learning community. As there was very little previous research which examined blogging as a medium for professional learning, particularly in the profession of ECEC, the theories generated through this study could be used to inform future research in this area. This is particularly significant as the College of Early Childhood Educators continues to promote their continuous professional 
learning program which includes blogging and engagement in virtual learning communities as potential professional learning activities. While the overall level of participation in this study was low, it allowed for an exploration of the barriers which may preclude RECEs from effectively using blogging for professional learning, and also allowed for the generation of further inquiries which could be examined in future research studies. 


\section{Appendix A}

\section{First Interview Guide}

Demographic Information

1. Gender

2. Age

3. Education level

4. Years in the ECEC field

1. Tell me about your practice as a Registered Early Childhood Educator.

2. How would measure your effectiveness as an RECE?

- Do you feel that you are currently effective?

- Could you be more effective?

3. What has the experience of writing a blog been like?

- Potential probes

- Time management

- WordPress/technology

- Confidentiality

4. What do you typically blog about?

5. Has blogging impacted your practice as a Registered Early Childhood Educator?

- If so, how?

6. Have you been reading and commenting on the other blogs?

- How has that impacted your practice?

7. What were you hoping to get out of this study? 


\section{Appendix B}

\section{Final Interview Questions}

1. In what ways has your experience writing the blog changed since the beginning of the study?

a. Have you experienced any challenges or encountered any barriers which may have limited or precluded your engagement with your blog?

2. What would you say that you typically blog about?

a. Has this been consistent throughout the four months?

b. Have you been making links between theory and practice through the content of your blogs?

c. Would you consider your blog posts to be reflective? (Does not need to be an exclusive yes/no answer)

3. In what ways has your experience of writing your blog and reading/commenting on the other blogs impacted your practice?

4. Do you feel that, through reading and commenting on each other blogs, relationships or a type of community has been formed?

5. Has your opinion of blogging changed since you participated in this study?

a. If so, how?

6. Will you continue this blog or would you consider writing another blog in the future? 


\section{Appendix C}

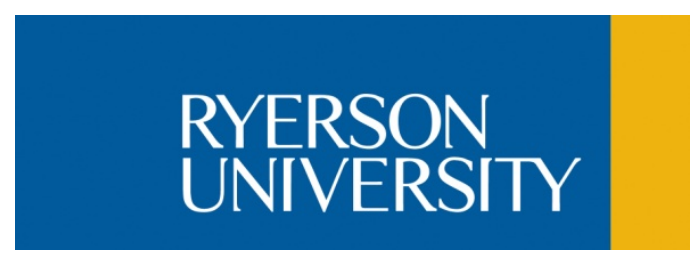

\section{Ryerson University}

\section{Consent Agreement}

You are being invited to participate in a research study. Please read this consent form so that you understand what your participation will involve. Before you consent to participate, please ask any questions to be sure you understand what your participation will involve.

Blogging in a Virtual Learning Community: is it effective continuous professional learning for Ontario Registered Early Childhood Educators?

INVESTIGATORS: This research study is being conducted by Shannon Sveda and Dr. Rachel Langford from the School of Early Childhood Studies at Ryerson University.

If you have any questions or concerns about the research, please feel free to contact Shannon Sveda via email at shannon.sveda@ryerson.ca.

\section{PURPOSE OF THE STUDY:}

This study is designed to explore the experience of blogging in an online community for early childhood educators. Six to ten Registered Early Childhood Educators, currently practicing in Ontario, are being recruited to create and maintain a weekly blog documenting their experiences in the field. Participants will also be asked to engage with each other through commenting on each other's blogs. In addition to the weekly blogs and comments, participants will be individually interviewed at three points during the study. This research is being 
completed as a Master's Research Project, and the results will be written up by Shannon Sveda as a Master's Research Paper. The findings will be written as a publishable manuscript.

\section{WHAT PARTICIPATION MEANS:}

If you volunteer to participate in this study, you will be asked to do the following things:

Prior to participation in the study

- Read, sign and submit the consent form

- Submit the following demographic information

0 Email address (used for communication)

o Education level

- Review the Terms of Service and Privacy Policy of Wordpress

- Create a blog using Wordpress (http://www.wordpress.com)

- Submit blog URL and chosen pseudonyms for themselves and their workplace to primary investigator

- Participants will receive the URLs of the other blogs in the study

For the duration of the study (Four months)

- Write a minimum of one blog post per week for the duration of the study

- Read and comment on at least one blog post written by another participant each week for the duration of the study

After one, two, and four months

- Complete a semi-structured interview with Shannon Sveda (the principal investigator) either in person or via telephone/Skype

- The interview will last 30 minutes to one hour

- Sample questions

o Tell me about your practice as a Registered Early Childhood Educator

0 What has the experience of writing a blog been like?

\section{At the conclusion of the study}

- You will have the option of requesting a summary of the research findings, which will be provided electronically

\section{POTENTIAL BENEFITS:}

Participation in this study could be used towards continuous professional learning, as described by the College of Early Childhood Educators, the regulatory body for Early Childhood Educators in Ontario. 
I cannot guarantee, however, that you will receive any benefits from participating in this study.

\section{WHAT ARE THE POTENTIAL RISKS TO YOU AS A PARTICIPANT:}

Participants are required to use a pseudonym in their blogging for both themselves and their workplace. Participants are not permitted to include photographs or identifying information (including names and locations) as the blogs created in this study will be available to the public. Participants are also required not to disclose their participation in this study to their colleagues and the families in their program. This will minimize the risk of personal identity being revealed and the risk of social exposure. Furthermore, participants are responsible to ensure that the creation of a work-related blog and their participation in this study does not violate the terms of their employment contract prior to participating in this study, in order to minimize the risk of job loss as a result of blogging about their work experiences. Participants will not be asked to blog about anything they are not comfortable with, and will be able to choose their own topics for blog posts to further minimize risk.

Participants are required to abide by the Code of Ethics and Standards of Practice established by the College of Early Childhood Educators, particularly with regards to the stipulations on confidentiality as per Standard IV: Confidentiality and Consent to the Release of Information Regarding Children and their Families.

\section{CONFIDENTIALITY:}

Participants will be assigned pseudonyms, different to those which they use on their blog, which will be used in data collection and in published material to ensure confidentiality.

Data gathered in the study, which includes blog posts, comments, and audio recordings from interviews will be stored electronically in a Google Drive folder, which is password protected and managed by Ryerson University. Only the primary investigator (Shannon Sveda) and faculty advisor (Dr. Rachel Langford) will have access to the audio recordings and gathered electronic data. Any hard copies of the data will be stored in a locked cabinet, with consent forms being stored separately from other data. All data will be stored for one year and then destroyed. 
Participants should be aware that because the blogs will be hosted by a third party and publicly available on the internet, individual privacy and confidentiality cannot be guaranteed.

\section{INCENTIVES FOR PARTICIPATION:}

Participants will not be paid to participate in this study.

\section{VOLUNTARY PARTICIPATION AND WITHDRAWAL:}

Participation in this study is completely voluntary. You can choose whether to be in this study or not. If any interview question makes you uncomfortable, you may skip that question. You may stop participating at any time. If you choose to stop participating, you may also choose to not have your data included in the study. As a participant, you will have control over your blog and will be able to delete your blog if you choose to withdraw from this study. Your choice of whether or not to participate will not influence your future relations with Ryerson University or the investigators Shannon Sveda and Dr. Rachel Langford involved in the research.

\section{QUESTIONS ABOUT THE STUDY:}

If you have any questions about the research now, please ask. If you have questions later about the research, you may contact.

Shannon Sveda

c/o Dr. Rachel Langford

Ryerson University

350 Victoria Street

Toronto, ON M5B 2K3

Phone Number: 416-979-5000

shannon.sveda@ryerson.ca 
This study has been reviewed by the Ryerson University Research Ethics Board. If you have questions regarding your rights as a participant in this study please contact:

Research Ethics Board

c/o Office of the Vice President, Research and Innovation

Ryerson University

350 Victoria Street

Toronto, ON M5B 2K3

416-979-5042

rebchair@ryerson.ca 
Blogging in a Virtual Learning Community: is it effective continuous professional learning for Ontario Registered Early Childhood Educators?

\section{CONFIRMATION OF AGREEMENT:}

Your signature below indicates that you have read the information in this agreement and have had a chance to ask any questions you have about the study. Your signature also indicates that you agree to participate in the study and have been told that you can change your mind and withdraw your consent to participate at any time. You have been given a copy of this agreement.

You have been told that by signing this consent agreement you are not giving up any of your legal rights.

Name of Participant (please print)

Signature of Participant

Date

I agree to be audio-recorded for the purposes of this study. I understand how these recordings will be stored and destroyed. I also understand that at any time I can request for the audiorecording to be halted, either temporarily or permanently. 


\section{Appendix D}

\section{Participants' Blog Posts by Code}

\begin{tabular}{|l|l|l|l|l|l|l|l|l|}
\hline & Dorothy & Eva & Julie & Katrina & Laura & Maria & Mary & Sonia \\
\hline Case Study & 0 & 4 & 0 & 0 & 0 & 0 & 0 & 0 \\
\hline $\begin{array}{l}\text { Community } \\
\text { Response }\end{array}$ & 1 & 0 & 0 & 0 & 0 & 0 & 0 & 0 \\
\hline Documentation & 7 & 3 & 4 & 0 & 0 & 0 & 0 & 12 \\
\hline Encouragement & 0 & 1 & 0 & 0 & 0 & 0 & 4 & 0 \\
\hline Goal Setting & 0 & 0 & 0 & 0 & 0 & 0 & 1 & 0 \\
\hline Inquiry & 5 & 4 & 1 & 0 & 0 & 2 & 5 & 13 \\
\hline Invitation & 0 & 0 & 0 & 0 & 1 & 0 & 0 & 0 \\
\hline $\begin{array}{l}\text { Participant } \\
\text { Information }\end{array}$ & 0 & 0 & 1 & 1 & 2 & 1 & 4 & 3 \\
\hline Planning & 2 & 0 & 0 & 0 & 0 & 1 & 0 & 3 \\
\hline Reflection & 6 & 5 & 7 & 0 & 2 & 1 & 3 & 8 \\
\hline Resource Sharing & 5 & 4 & 3 & 0 & 2 & 0 & 0 & 8 \\
\hline $\begin{array}{l}\text { Response to } \\
\text { Inquiry }\end{array}$ & 1 & 0 & 0 & 0 & 0 & 0 & 0 & 0 \\
\hline
\end{tabular}




\section{Appendix E}

\section{Comment Codes by Blog Post}

\begin{tabular}{|c|c|c|c|c|c|c|c|c|c|c|}
\hline Participant & Blog Post & Comments & $\begin{array}{c}\text { Author } \\
\text { Response } \\
\end{array}$ & Correction & Encouragement & Inquiry & Reflection & Response & $\begin{array}{c}\text { Story } \\
\text { Sharing }\end{array}$ & Suggestion \\
\hline \multirow{10}{*}{ Dorothy } & Every Child is an Artist & 8 & 3 & 0 & 1 & 2 & 7 & 1 & 1 & 0 \\
\hline & Untitled & 1 & 0 & 0 & 1 & 0 & 0 & 0 & 0 & 0 \\
\hline & Art in Kindergarten & 2 & 1 & 0 & 0 & 1 & 1 & 0 & 0 & 1 \\
\hline & \begin{tabular}{|l|} 
Documentation \\
\end{tabular} & 0 & 0 & 0 & 0 & 0 & 0 & 0 & 0 & 0 \\
\hline & Loose parts 2 & 0 & 0 & 0 & 0 & 0 & 0 & 0 & 0 & 0 \\
\hline & Loose parts & 5 & 3 & 0 & 0 & 1 & 2 & 2 & 0 & 4 \\
\hline & Mix it up! & 1 & 0 & 0 & 1 & 0 & 0 & 0 & 0 & 0 \\
\hline & School inquiry & 0 & 0 & 0 & 0 & 0 & 0 & 0 & 0 & 0 \\
\hline & STEAM Parent Conference & 0 & 0 & 0 & 0 & 0 & 0 & 0 & 0 & 0 \\
\hline & Storytelling & 1 & 0 & 0 & 0 & 0 & 0 & 0 & 1 & 0 \\
\hline \multirow{14}{*}{ Sonia } & A Spark!-Rainbows & 5 & 2 & 0 & 0 & 0 & 0 & 0 & 0 & 3 \\
\hline & Adventures In Kindergarten & 0 & 0 & 0 & 0 & 0 & 0 & 0 & 0 & 0 \\
\hline & $\begin{array}{l}\text { Check out this great idea of } \\
\text { storing children's artwork! }\end{array}$ & 0 & 0 & 0 & 0 & 0 & 0 & 0 & 0 & 0 \\
\hline & Easter Sensory Bin & 4 & 2 & 0 & 0 & 1 & 0 & 0 & 0 & 1 \\
\hline & Easter Sensory Bin Pics & 0 & 0 & 0 & 0 & 0 & 0 & 0 & 0 & 0 \\
\hline & Last Day Of School & 0 & 0 & 0 & 0 & 0 & 0 & 0 & 0 & 0 \\
\hline & Mix It Up! & 2 & 1 & 0 & 1 & 0 & 0 & 0 & 0 & 0 \\
\hline & Our Year Is Coming To An End & 0 & 0 & 0 & 0 & 0 & 0 & 0 & 0 & 0 \\
\hline & Outdoor Play & 4 & 2 & 0 & 0 & 1 & 0 & 2 & 0 & 0 \\
\hline & Outside Playtime & 1 & 0 & 0 & 0 & 0 & 0 & 1 & 0 & 1 \\
\hline & Rainbows!-Continued & 0 & 0 & 0 & 0 & 0 & 0 & 0 & 0 & 0 \\
\hline & Welcome Spring! & 1 & 0 & 0 & 1 & 0 & 0 & 0 & 0 & 0 \\
\hline & What is A Provocation & 0 & 0 & 0 & 0 & 0 & 0 & 0 & 0 & 0 \\
\hline & Worm Garden & 1 & 0 & 0 & 1 & 1 & 0 & 1 & 0 & 0 \\
\hline
\end{tabular}




\begin{tabular}{|c|c|c|c|c|c|c|c|c|c|c|}
\hline & Yes... & 0 & 0 & 0 & 0 & 0 & 0 & 0 & 0 & 0 \\
\hline \multirow[b]{2}{*}{ Laura } & Navigating & 1 & 0 & 0 & 0 & 0 & 0 & 1 & 0 & 0 \\
\hline & $\begin{array}{l}\text { Technology \& Learning \& } \\
\text { Tweeting -OH MY! }\end{array}$ & 0 & 0 & 0 & 0 & 0 & 0 & 0 & 0 & 0 \\
\hline \multirow{5}{*}{ Mary } & Hello Educators! & 2 & 1 & 0 & 0 & 0 & 0 & 1 & 0 & 0 \\
\hline & It’s A New Day! & 0 & 0 & 0 & 0 & 0 & 0 & 0 & 0 & 0 \\
\hline & Juggling Life & 2 & 0 & 0 & 0 & 0 & 1 & 2 & 0 & 0 \\
\hline & Just Another Week & 0 & 0 & 0 & 0 & 0 & 0 & 0 & 0 & 0 \\
\hline & $\begin{array}{l}\text { What have you done for you } \\
\text { lately }\end{array}$ & 1 & 0 & 0 & 0 & 0 & 0 & 1 & 0 & 0 \\
\hline \multirow{8}{*}{ Eva } & $\begin{array}{l}\text { Exploring Creativity \& } \\
\text { Intelligence }\end{array}$ & 1 & 0 & 0 & 0 & 0 & 0 & 1 & 0 & 0 \\
\hline & Handwashing for a good score & 2 & 1 & 0 & 0 & 1 & 0 & 1 & 0 & 0 \\
\hline & Intention versus Score & 0 & 0 & 0 & 0 & 0 & 0 & 0 & 0 & 0 \\
\hline & Meal Times - Is it a stressor & 2 & 1 & 0 & 0 & 0 & 0 & 1 & 1 & 0 \\
\hline & Nature in the classroom & 0 & 0 & 0 & 0 & 0 & 0 & 0 & 0 & 0 \\
\hline & Nature in the Classroom 2 & 0 & 0 & 0 & 0 & 0 & 0 & 0 & 0 & 0 \\
\hline & $\begin{array}{l}\text { Shared Space for School Age } \\
\text { children }\end{array}$ & 6 & 2 & 2 & 0 & 1 & 1 & 4 & 0 & 0 \\
\hline & Spring & 5 & 2 & 0 & 0 & 0 & 0 & 3 & 0 & 0 \\
\hline Katrina & Hello Fellow Bloggers & 6 & 3 & 0 & 2 & 0 & 0 & 1 & 0 & 1 \\
\hline \multirow{6}{*}{ Julie } & End of Winter Blues & 4 & 1 & 0 & 0 & 0 & 1 & 3 & 0 & 3 \\
\hline & Puddles and Jumpers & 2 & 0 & 0 & 1 & 0 & 0 & 2 & 0 & 0 \\
\hline & Styrofoam and Screws & 0 & 0 & 0 & 0 & 0 & 0 & 0 & 0 & 0 \\
\hline & Super Heroes & 0 & 0 & 0 & 0 & 0 & 0 & 0 & 0 & 0 \\
\hline & We can do this......... & 0 & 0 & 0 & 0 & 0 & 0 & 0 & 0 & 0 \\
\hline & You Have To Start Some Where & 1 & 0 & 0 & 0 & 0 & 0 & 1 & 0 & 0 \\
\hline \multirow{2}{*}{ Maria } & $\begin{array}{l}\text { Provocations for Capacity, Mass, } \\
\text { and Volume! Help! }\end{array}$ & 0 & 0 & 0 & 0 & 0 & 0 & 0 & 0 & 0 \\
\hline & $\begin{array}{l}\text { Welcome to my World of Early } \\
\text { Childhood! }\end{array}$ & 0 & 0 & 0 & 0 & 0 & 0 & 0 & 0 & 0 \\
\hline
\end{tabular}




\section{Appendix F}

\section{First Interview Codes}

Demographics

- 1-Gender

- 2-Age

- 3- Education Level

- 4- Years in Field

1-Practice

- Child Care

- FDK

- Training
o Post-Secondary
o Staff \& Program Support

2-Efficacy

- Yes

- No

- More Effective
o Yes
o No

3-Experience Blogging

- Barriers
o Knowing What To Write
o No Response
o Technology
o Time
o Writing Confidence

- Positive
o Accessible
o Easy to Start

\section{4-Blog Content}

- Audience

- Explore Quality Practice

- Process 
- Reflection

- Seeking Feedback

- Sharing Activities

- Sharing Information/Resources

- Whatever Comes to Mind

5-Blog Impact

- Yes

o Idea Sharing

o Reflection

- No

o Potential

- Desire to Impact Others

6-Community

- Barriers
o Blog Length
o Distraction
o Participation
o Time

- Positive

o Seeking Information/Ideas

o Sharing Experiences

o Similar Ideas/Experiences

- Creating

7-Why Study

- Desire to Start Blog

- Information Sharing

- Interest

- Keep Up With Field

- More Experience/Understanding

- Networking

- Professional Growth

Final Interview Codes

1-Experience Blogging

- Barriers 


$$
\begin{array}{ll}
\text { o } & \text { Commitment } \\
\text { o } & \text { Content } \\
\text { o } & \text { Interest } \\
\text { o } & \text { Photos } \\
\text { o } & \text { Technology } \\
\text { o } & \text { Time }
\end{array}
$$

- Positive

- Community

- Frustration

- Understanding Blogging

2-Blog Content

- Programming

- Promotion of Quality Practice

- Seeking Feedback

- Consistency

$$
\begin{array}{ll}
\text { o } & \text { Yes } \\
\text { o } & \text { No }
\end{array}
$$

- Reflective
o Yes
o Sometimes
o Community

- Theory-Practice

$$
\text { o Yes }
$$

3-Practice Impact

- Different Perspectives

- Feedback

4-Community

- Yes

- No

o Not Enough Exchanges

\section{5-Blogging Opinion}

- Yes

- No

6-Blogging Future 
- Positive

Professional Learning 


\section{References}

AECEO. (2014). Position Paper on Professional Learning for Registered Early Childhood Educators. Retrieved from http://www.aeceo.ca/postion_paper_on_professional_learning_for_registered_earl y_childhood_educators

Alvestad, M., \& Röthle, M. (2007). Educational Forums: frames for development of professional learning. A project in early childhood education in Norway. European Early Childhood Education Research Journal, 15(3), 407-425. doi:10.1080/13502930701679692

Byington, T. A. (2011). Communities of practice: Using blogs to increase collaboration. Intervention in School and Clinic, 46(5), 280-291. doi:10.1177/1053451210395384

Cherrington, S., \& Thornton, K. (2013). Continuing professional development in early childhood education in New Zealand. Early Years, 33(2), 119-132. doi:10.1080/09575146.2013.763770

College of Early Childhood Educators. (2011). Code of Ethics and Standards of Practice. College of Early Childhood Educators.

College of Early Childhood Educators. (2013a). Continuous Professional Learning Program Development Process. Retrieved November 2013, from College of Early Childhood Educators: http://www.collegeece.ca/en/Documents/CPL_feedback_booklet_2013.pdf 
College of Early Childhood Educators. (2013b). FAQ - Proposed Continuous

Professional Learning Regulation. Retrieved December 5, 2013, from College of Early Childhood Educators: http://www.collegeece.ca/en/Documents/Proposed_CPL_Regulation_FAQ.pdf

College of Early Childhood Educators. (2014a). Reflective Practice and Self-Directed Learning. Retrieved from College of Early Chidhood Educators: http://www.collegeece.ca/en/Members/Documents/Reflective\%20Practice\%20and\%20SelfDirected\%20Learning\%20Booklet\%20September\%201\%202014.pdf

College of Early Childhood Educators. (2014b). The CPL program is here. Retrieved December 15, 2014, from College of Early Childhood Educators: http://www.college-ece.ca/en/Members/Pages/CPL-Program.aspx

Creswell, J. W. (2014). Research design: qualitative, quantitative, and mixed methods approaches (4th ed.). Thousand Oaks, California: SAGE Publications, Inc. .

Dewey, J. (1910). How We Think. USA: D. C. Heath \& Co. .

Dictionary.com Unabridged. (2015). Technology. Retrieved from Dictionary.com Unabridged: http://dictionary.reference.com/browse/technology

Early Childhood Educators Act. (2007). S.O. 2007, CHAPTER 7, SCHEDULE 8. Retrieved from http://www.elaws.gov.on.ca/html/statutes/english/elaws_statutes_07e07_e.htm 
Edwards, S., \& Nuttall, J. (Eds.). (2009). Professional Learning in Early Childhood Settings. Rotterdam, The Netherlands: Sense Publishers.

Fleet, A., \& Patterson, C. (2009). A Timescape. In S. Edwards, \& J. Nutall (Eds.), Professional Learning in Early Childhood Settings (pp. 9-26). Rotterdam, The Netherlands: Sense Publishers.

Harland, D. J., \& Wondra, J. D. (2011). Preservice teachers' reflection on clinical experiences: A comparison of blog and final paper assignments. Journal of Digital Learning in Teacher Education, 27(4), 128-133.

Killeavy, M., \& Moloney, A. (2010). Reflection in a social space: Can blogging support reflective practice for beginning teachers? Teaching and Teacher Eduation, 26, 1070-1076.

Lehrer, J. S. (2013). Accompanying early childhood professional reflection in Quebec: A case study. Early Years, 33(2), 186-200. doi:10.1080/09575146.2013.781136

Lin, H. T., \& Yuan, S. M. (2006). Taking Blog as a Platform of Learning Reflective Journal. In W. Liu, Q. Li, \& R. W. Lau (Eds.), Advances in Web Based Learning ICWL 2006 (pp. 38-47). Penang, Malaysia: Springer Berlin Heidelberg.

Lindgren, A.-L. (2012). Ethical issues in pedagogical documentation: Representations of children through digital technology. International Journal of Early Childhood, 44(3), 327-340. doi:10.1007/s13158-012-0074-x 
Luehmann, A. L. (2008). Using Blogging in Support of Teacher Professional Identity Development: A Case Study. The Journal of the Learning Sciences, 17, 287-337. doi:10.1080/10508400802192706

Luehmann, A. L., \& Tinelli, L. (2008). Teacher professional identity development with social networking technologies: learning reform through blogging. Educational Media International, 45(4), 323-333. doi:10.1080/09523980802573263

McDaniel, B. T., Coyne, S. M., \& Holmes, E. K. (2012). New mothers and media use: Associations between blogging, social networking, and maternal well-being. Maternal and Child Health Journal, 16, 1509-1517. doi:10.1007/s10995-0110918-2

Merriam-Webster, Incorporated. (2013). Blog. Retrieved November 2013, from MerriamWebster.com: http://www.merriam-webster.com/dictionary/blog

Nielsen. (2012). State of the Media: The Social Media Report 2012. Nielsen. Retrieved December 7, 2013, from http://www.neilsen.com

Oberhuemer, P. (2005). Conceptualising the early childhood pedagogue: Policy approaches and issues of professionalism. European Early Childhood Education Research Journal, 13(1), 5-16.

OECD. (2012). Starting Strong III: A Quality Toolbox for Early Childhood Education and Care. OECD Publishing. doi:10.1787/9789264123564-en

Oktay, J. S. (2012). Grounded Theory. New York, New York: Oxford University Press, Inc. doi:10.1093/acprof:oso/9780199753697.001.0001 
Opfer, V. D., \& Pedder, D. (2011). Conceptualizing teacher professional learning. Review of Educational Research, 81(3), 376-407. doi:10.3102/0034654311413609

Orlikowski, W. J. (1992). The duality of technology: Rethinking the concept of technology in organizations. Organization Science, 3(3), 398-427.

Powell, G., \& McCauley, A. W. (2012). Blogging as a way to promote familyprofessional partnerships. Young Exceptional Children, 15(2), 20-31. doi:10.1177/1096250611428491

QSR International Pty Ltd. (2013). NVivo Overview. Retrieved December 6, 2013, from QSR International: http://www.qsrinternational.com/products_nvivo.aspx

Recchia, S. L., \& Beck, L. M. (2014). Reflective practice as "enrichment": How new early childhood teachers enact preservice values in their classrooms. Journal of Early Childhood Teacher Education, 35, 203-225. doi:10.1080/10901027.2014.936074

Rodgers, C. (2002). Defining Reflection: Another Look at John Dewey and Reflective Thinking. Teachers College Record, 104(4), 842-866.

Schön, D. A. (1983). The Reflective Practitioner. United States of America: Basic Books, Inc.

Shoffner, M. (2009). Personal attitudes and technology: implications for preservice teacher reflective practice. Teacher Education Quarterly, 36(2), 143.

Shore, R. A. (2012). Professional development for early childhood education: A national perspective. NHSA Dialog, 15(1), 1-7. doi:10.1080/15240754.2012.638560 
Sobrero, P. M. (2008). Essential components for successful virtual learning communities. Journal of Extension, 46(4). Retrieved from http://www.joe.org/joe/2008august/a1.php

Stavrositu, C., \& Sundar, S. S. (2012). Does Blogging Empower Women? Exploring the Role of Agency and Community. Journal of Computer-Mediated Communication, 17, 369-386. doi:10.1111/j.1083-6101.2012.01587.x

Stiler, G. M., \& Philleo, T. (2003). Blogging and blogspots: An alternative format for encouraging reflective practice among preservice teachers. Education, 123(4), 789-796.

Wenger, E. (1998). Communities of Practice: Learning as a Social System. Systems Thinker. Retrieved from http://www.co-i-l.com/coil/knowledgegarden/cop/lss.shtml

Willis, J. W. (2007). Foundations of Qualitative Research: Interpretive and Critical Approaches. Thousand Oaks, California: SAGE Publications, Inc. doi:dx.doi.org/10.4135/9781452230108

Wood, E., \& Bennett, N. (2000). Changing theories, changing practice: Exploring early childhood teachers' professional learning. Teaching and Teacher Education, 16, 635-647.

Wordpress.com. (2015). Stats. Retrieved from Worpress.com: http://wordpress.com/activity/ 
Yang, S.-H. (2009). Using Blogs to Enhance Critical Reflection and Community of Practice. Educational Technology \& Society, 12(2), 11-21. 